\title{
¿DERECHO NATURAL O MORAL? COMENTARIOS CRÍTICOS A "DERECHO Y MORAL (RAZÓN PRÁCTICA): CONEXIONES EN TIEMPOS DEL ESTADO DE DERECHO CONSTITUCIONAL DE RODOLFO VIGO”*
}

\author{
¿NATURAL OR MORAL LAW? CRITICAL COMMENTS TO RODOLFO \\ VIGO'S LAW AND MORALITY (PRACTICAL REASON): CONNECTIONS \\ IN TIMES OF THE CONSTITUCIONAL RULE OF LAW
}

\author{
Javier SALDAÑA SERRANO**
}

\section{Resumen:}

El artículo analiza críticamente la propuesta planteada por Rodolfo Luis Vigo en este número en torno a las nueve conexiones identificables en el llamado Estado constitucional de derecho. Siguiendo esta discusión, en cambio, se plantea la pregunta: ¿cómo abordaría el derecho natural —y no la morallas cuestiones iusfilosóficas en el actual Estado constitucional de derecho? Así, el autor busca explicar cómo es que el derecho natural puede ofrecer respuestas sólidas a las cuestiones iusfilosóficas planteadas en el escrito del profesor Vigo, y sostiene que el derecho natural de corte clásico está en mejores condiciones de abordar muchas de las problemáticas planteada por la actual filosofía del derecho y, en consecuencia, puede seguir hablándose de derecho natural sin necesidad de recurrir a la moral.

\section{Palabras clave:}

Derecho natural, moral, validez, razón práctica, derecho positivo.

\section{Abstract:}

The article critically analyzes the proposal put forward by Rodolfo Luis Vigo in this issue regarding the nine identifiable connections in the so-called

Artículo recibido el 10 de octubre de 2020 y aceptado para su publicación el 14 de diciembre de 2020 .

** Investigador en el Instituto de Investigaciones Jurídicas de la UNAM, y profesor de la materia Filosofía del Derecho de la Facultad de Derecho de la UNAM. Correo: javiers@unam.mx, ORCID: https://orcid.org/0000-0002-2050-034X.

Problema. Anuario de Filosofía y Teoría del Derecho, núm. 15, enero-diciembre de 2021, pp. 97-146 Ciudad de México, ISSN 2007-4387, se distribuye bajo una Licencia Creative Commons Reconocimiento- 
JAVIER SALDAÑA SERRANO

Constitutional Rule of Law. Following this discussion, however, the question arises: How would natural law — and not morality - address philosophical questions in the current constitutional rule of law? Thus, the author seeks to explain how natural law can offer solid answers to the ius-philosophical questions raised in Professor Vigo's paper, and argues that classical natural law is in a better position to address many of the issues raised by the current philosophy of law and, consequently, it is possible to talk about natural law without resorting to morality.

Keywords:

Natural Law, Morality, Validity, Practical Reason, Statutory Law. 
¿DERECHO NATURAL O MORAL? COMENTARIOS CRÍTICOS...

SumArio: I. Planteamiento del problema. II. El derecho natural como limite de validez del derecho positivo. III. El derecho natural asegura la creación de un mejor derecho. IV. El derecho natural como elemento garantizador de la mejor aplicación del derecho. V. El derecho natural como base de un mejor conocimiento del derecho. VI. El derecho natural como limite al cumplimiento de la norma jurídica. VII. El derecho natural como facilitador de la eficacia del derecho. VIII. El derecho natural como complemento de la coacción jurídica. IX. El derecho natural abierto a otros saberes cientificos. X. El derecho natural como elemento garantizador de los mejores operadores juridicos (principalmente los jueces). XI. Conclusiones. XII. Referencias.

\section{Planteamiento DEL PRoblema}

No se comete ninguna imprecisión si se afirma que uno de los tópicos más recurrentemente citados en la filosofía del derecho contemporánea es el que se refiere a la vinculación entre el derecho y la moral. Así, a lo largo de la historia del pensamiento occidental no ha existido filósofo del derecho importante que no se haya avocado a su tratamiento, sea para defender esta tesis o para rechazarla. Para algunos, existe una vinculación, no sólo contingente, sino incluso necesaria entre dichos ordenamientos normativos. Para otros, en cambio, entre ambos hay un abismo infranqueable que imposibilita algún tipo de conexión. Incluso no ha faltado quien afirme que el tratamiento de la vinculación/separación derecho-moral es el tema que se encuentra en el corazón mismo de la filosofía del derecho. ${ }^{1}$

Queda claro entonces que no es un tema baladí, sino que representa una gran empresa intelectual, cuyo tratamiento amerita, sin

1 Para una visión general de la discusión sobre la relación/separación entre el derecho y la moral, cfr. Garzón, Valdés, Ernesto, "Derecho y Moral”, en Vázquez, R. (comp.), Derecho y moral. Ensayos sobre un debate contemporáneo, Barcelona, Gedisa, 1998, pp. 19-55. Cfr. Maccormick, Neil, "Natural Law and the Separation of Law and Morals", en George, Robert, P. (ed.), Natural Law Theory. Contemporary Essays, Oxford, Oxford University Press, 1995, pp. 105-133. 
duda, un conocimiento amplio y profundo, tanto de escuelas antagónicas como de corrientes de pensamiento afines a la vinculación entre el derecho y la moral. Esta última nota es la característica identificable en el profesor argentino Rodolfo Luis Vigo, quien en el trabajo que a continuación comentamos intenta superar la supuesta rivalidad entre dichos sistemas normativos, proponiendo, a la vez, nueve conexiones identificables en el llamado Estado constitucional de derecho, el cual, como sabemos, ha cogido especial fuerza en los últimos años. A la luz de lo que se ha señalado cabría preguntarse: ¿es posible seguir sosteniendo la separación entre el derecho y la moral, o cabe hoy un replanteamiento de ese distanciamiento?

Sin duda, resulta ser un esfuerzo encomiable el desplegado por el profesor argentino y demuestra ese impulso constante por entrar en diálogo con las distintas propuestas contemporáneas iusfilosóficas, incluso antagónicas a sus bases epistemológicas. En este punto hay, sin embargo, una inquietud intelectual que en mi caso es ya de larga data, a saber ¿el derecho natural enraizado en Aristóteles, la jurisprudencia romana clásica, Tomás de Aquino y recientemente defendido por el profesor emérito de la Universidad de Oxford John Finnis, estaría en condiciones de ofrecer respuestas a éstas y otras conexiones de las que trata Vigo? Dicho de otra manera, ¿Cómo abordaría el derecho natural -y no la moral- las cuestiones iusfilosóficas en el actual Estado constitucional de derecho? ¿Es necesario remitirnos a la moral para evidenciar esas relaciones existentes, o basta una cabal comprensión del derecho natural para reconocer objetivamente las mismas?

En lo que sigue trataré de explicar cómo el derecho natural puede ofrecer respuestas sólidas a las cuestiones iusfilosóficas planteadas en el escrito del profesor Vigo, o, al menos, establecer sus bases más generales para la comprensión de las mismas. Para esto procederé del siguiente modo. En primer lugar, trataré de presentar lo que considero es el argumento central en cada uno de los puntos que el profesor argentino ofrece, y a partir de aquí trataré de explicar las posibles respuestas teóricas que en el derecho natural se pueden encontrar. De este modo, la tesis entonces a defender aquí es que el derecho natural de corte clásico está en mejores condiciones de abordar muchas de las problemáticas planteada por la actual filo- 
sofía del derecho y, en consecuencia, puede seguir hablándose de derecho natural sin necesidad de recurrir a la moral.

Lo que se acaba de apuntar no puede llevarnos a confusión y hacernos creer que la moral resultaría inútil en el debate de las reflexiones iusfilosóficas actuales, mucho menos querrá decir que se rechace a la moral. La tesis de la que parto en las líneas que siguen es que hay una conexión entre el derecho y la moral dado que ambos órdenes normativos no son autónomos, pero hay que aclarar que cuando se habla de derecho - como es el caso del derecho naturalno se está hablando de moral, por muy íntima que sea la relación entre ambos. El derecho natural es derecho, no es moral, más aún, en orden de importancia y prelación lo «justo», como derecho, es previo al deber de moral de justicia. ${ }^{2}$

Lo último que he de señalar es que refiriéndose este trabajo al derecho natural aristotélico-tomista, trataré de citar sólo las fuentes directas de los autores clásicos, y sólo también aquella parte de la doctrina más autorizada para tratar el tema. No está de más señalar que en cada uno de los encabezados que compone este trabajo he decidido sustituir la palabra "moral" que utiliza Vigo, por la de "derecho natural", esto para ubicar el contenido al que se referirá el epígrafe en cuestión.

\section{EL DERECHO NATURAL COMO LÍMITE DE VALIDEZ DEL DERECHO POSITIVO}

La tesis central en esta parte del trabajo es relativamente sencilla. Refiriéndose al positivismo jurídico, Rodolfo Vigo dirá que para tal corriente una norma jurídica sería considerada justa por el sólo hecho de haber sido dada por la voluntad del legislador, representante éste de la voluntad popular, sin admitir, claro está, ningún cuestionamiento ético. Señalará en la parte conducente lo siguiente:

...La existencia o validez del derecho requiere la dimensión institucional (órganos, normas y sistema) y cierta eficacia social, pero hay que su-

2 Cfr. Boyle, Joseph, "Natural Law and the Ethics of Traditions", en Robert, P. George (ed.), Natural Law Theory. Contemporary Essays, Oxford, Oxford University Press, 1995, pp. 3-30. 
marle un tercer requisito ya no positivista: el juzgamiento de su contenido ético objetivo en orden a confirmar que no supera el umbral de la injusticia extrema.

Más adelante sostiene dos argumentos que vendrían a completar su tesis central: "Si un jurista renuncia a incluir en su mirada a la perspectiva de una moral racional corre el riesgo de tener que aceptar o validar que existen normas en el derecho no obstante que a tenor ético de su contenido o su gestación no corresponde que así se las reconozca". Sentenciando:

Hay un contenido moral objetivo y mínimo pero infranqueable que la razón le pone a la autoridad con competencia jurígena, y ese es el valor con los que se consagra el «coto vedado» o la «juridicidad indisponible» de los derechos humanos según los Tratados respectivos, los que simplemente se limitan a reconocerlo (no los crean), en el espacio universal y con el carácter de inalienables (por cualquier voluntad pública o privada).

Como puede observarse, el argumento central tiene que ver con el tema de la validez o existencia del derecho, y la pregunta obligada en este punto sería: ¿una norma jurídica sólo es válida en la medida en que responde a los requisitos formales previamente establecidos para su creación, o tal existencia depende de algo más al mero requisito formal?

Hasta ahora, la teoría dominante de la validez jurídica ha sido exclusivamente la del positivismo jurídico, teniendo como su representante más conspicuo a Hans Kelsen. Este autor en diferentes lugares de su obra se refiere al tema, así, por ejemplo, en las primeras páginas de la Teoría Pura del Derecho llegará a afirmar:

Con el término «validez» designamos la existencia específica de una norma. Cuando describimos el sentido, o el significado, de un acto que instituye una norma, decimos que, con el acto en cuestión, cierto comportamiento humano es ordenado, mandado, prescripto, preceptuado, prohibido; o bien, admitido, permitido, autorizado. ${ }^{3}$

3 Kelsen, Hans, Teoría Pura del Derecho, 16a. ed., México, Porrúa, 2009, p. 23. 
Quien, sin embargo, habría de resumir de la mejor manera posible la tesis kelseniana sobre la validez jurídica, fue el profesor argentino Carlos Santiago Nino. Para este autor, el tema de la validez puede ser enfocado desde tres perspectivas o puntos de vista. En su libro La validez del derecho, Nino señala claramente que para Kelsen el tema de la validez puede ser observado del siguiente modo: En primer lugar, predicar la validez de un sistema jurídico o de una norma jurídica es afirmar que tiene fuerza vinculante. ${ }^{4}$ Aquí, sólo las normas que han sido establecidas por una autoridad legitimada para ello obligan, o vinculan a quienes van dirigidas. ${ }^{5}$

En segundo lugar - dice Nino-, la validez en Kelsen está igualmente asociada a su existencia, es decir, por validez de una norma entendemos que ésta existe en el ordenamiento jurídico, y si se niega o desconoce su validez entonces tal norma o tal sistema simplemente no existe.

En tercer lugar, la manera más significativa de entender la validez en Kelsen, según Nino, es la idea de que ésta no es puramente de carácter descriptiva, sino esencial y fundamentalmente normativa.

En la teoría de Kelsen la validez de una norma jurídica requiere que su dictado sea autorizado por otra norma que es, ella misma, válida. El juicio de que cierta norma es válida presupone, por lo tanto, un juicio de que otra norma, que autoriza la creación de la primera sea válida. ${ }^{6}$

Es evidente que para la teoría antes descrita el acento se pone en los aspectos puramente formales de obligatoriedad y existencia de las normas, no habiendo ninguna referencia a alguna cuestión ética, al menos esto es muy claro en los dos primeros significados que se ofrecen para entender la validez jurídica, pero ¿se podrá decir lo mismo del tercer modo en que aborda Nino el problema? La respuesta positivista diría que sí, que en rigor una norma es válida porque otra anterior lo determina, fijando su atención nuevamente en los aspectos formales que ésta establece. Sin embargo, todos sa-

4 Santiago Nino, Carlos, La validez del derecho, Buenos Aires, Astrea, 2003, p. 9.

5 Cfr. idem.

6 Cfr. ibidem, p. 11. 
bemos que tal respuesta es insuficiente, porque reconocer, como lo hace Nino, que la validez kelseniana no es puramente descriptiva, sino esencialmente normativa, nos lleva necesariamente a preguntarnos: ¿por qué es normativa la validez de una norma?, y la respuesta a esta pregunta no la pueden dar sólo los aspectos formales del positivismo jurídico, la respuesta tiene, necesariamente, que remitirnos a una concepción más amplia de validez que la pura remisión a una norma anterior.

Esta visión ampliada de validez jurídica de las normas, es decir, de su existencia y obligatoriedad, ha estado siempre presente en el centro mismo de la explicación sobre el derecho a lo largo de la historia, y ha sido precisamente el iusnaturalismo aristotélico-tomista el que mejor ha dado cuenta de ella. Para comprender lo señalado, lo primero que se debe considerar es que el derecho natural del que hablamos no es un ideal, ni algo irracional, "lo justo" es una realidad jurídica válida, justificada racionalmente y en consecuencia obligatoria para cualquier jurista. Así, por ejemplo, si sólo consideráramos el caso específico de la ley, tendríamos que decir que para autores iusnaturalistas como Tomás de Aquino, dos serían los argumentos centrales para reconocer su existencia jurídica y por tanto su validez: i) una justificación racional de la ley, y ii) el anclaje moral o ético de ésta en el bien común, lo cual permite asumirla como obligatoria por parte de sus destinatarios y de las autoridades.

Por lo que respecta al primer punto, varios son los lugares donde el Aquinate se pregunta si la ley pertenece a la razón. Uno de estos es el texto de la Summa Tehologiae q. 90, a.1, respondiéndose en la solución que

La ley es una regla y medida de nuestros actos según la cual uno es inducido a obrar; pues ley deriva de ligar; porque obliga en orden a la acción. Ahora bien, la regla y medida de nuestros actos es la razón que, como ya vimos (q.1 a.1. ad. 3), constituye el primer principio de los actos humanos, puesto que propio de la razón es ordenar al fin... sígase, pues, que la ley es algo que pertenece a la razón. ${ }^{7}$

7 Tomás de Aquino, Summa Tehologiae, I-II, q. 90, a 1. 


\section{¿DERECHO NATURAL O MORAL? COMENTARIOS CRÍTICOS...}

Como se puede desprender de lo anterior, la ley no sólo es producto de la razón, sino que es ésta el parámetro con el que medimos nuestras acciones. La razón, en términos tomistas, como dice Graneris, expresa las necesarias relaciones que hay en las cosas y es capaz de plasmarlas en fórmulas que constituyen las normas de la vida humana. ${ }^{8}$ Así, siendo entonces esta facultad humana la que delibera sobre lo que es bueno o malo en el hombre, la ley - producto de ésta- establecerá los límites a observar en el comportamiento humano, límites que no pueden ser otros que aquellos que faciliten el bien (o los bienes) del hombre, ayudándoles a ser mejores, y no participando con lo que le puede ser oprobioso o dañino para ellos. Volveremos sobre este punto en el siguiente argumento.

El segundo argumento esencial en la consideración iusnaturalista sobre la validez de la norma viene a reforzar el sustento moral del que hablamos, este se refiere al bien común social. Así, para el iusnaturalismo que venimos describiendo, una ley no sólo es válida porque sea producto de la razón en aquello que facilite el bien (o los bienes) del hombre, sino que ha de tener necesariamente un reflejo en el bien común de la sociedad en la que ésta se da. Efectivamente, la ley no puede tomar en cuenta el bien de cada persona considerada en forma aislada, sino que por la misma naturaleza social del hombre éste alcanza su más amplio desarrollo y perfección humana en la comunidad.

También aquí la tradición iusnaturalista tiene mucho que decirnos. Es el mismo Aristóteles quien en la Ética a Nicómaco deja perfectamente establecido que la ley está ordenada al bien común, al bien de la polis. Dice al respecto el de Estagira: “...llamamos justo a lo que produce o preserva la felicidad o sus elementos para la comunidad política". ${ }^{9}$ Como se alcanza a ver, será entonces el bien general de la comunidad política la razón por la que la ley aparece como norma obligatoria de una vida humana a realizarse en comunidad.

Tomás de Aquino, por su parte, señala del mismo modo en la misma Summa Tehologiae I-II, q. 90, pero esta vez en su artículo 2,

8 Graneris, Giuseppe, Contribución tomista a la filosofía del derecho, Buenos Aires, Eudeba, 1973, p. 35.

9 Aristóteles, Ética Nicomáquea, V, 1, 1129b, 20. 
...De donde se sigue que, como la ley se constituye primariamente por el orden al bien común, cualquier otro precepto sobre actos particulares no tiene razón de ley sino en cuanto se ordena al bien común. Se concluye, pues, que toda ley se ordena al bien común. ${ }^{10}$

Como se puede comprobar, la validez de una norma para el derecho natural viene determinada tanto por su racionalidad como por su contenido ético, pero va más allá, al incorporar un tercer elemento para que la ley sea válida, este es el tema de su necesaria promulgación. El Aquinate expresamente en la misma Summa Tehologiae I-II, q. 90, a. 4 establecerá de manera inequívoca la necesidad de dicha promulgación:

...Luego, para que la ley tenga el poder de obligar, lo cual compete a su naturaleza, es necesario que sea aplicada a los hombres que han de ser regulados conforme a ella. Esta aplicación se lleva a cabo al poner la ley en conocimiento de sus destinatarios mediante su promulgación. Luego la promulgación es necesaria para que la ley tenga fuerza de tal. ${ }^{11}$

Hasta aquí, podemos comprobar cómo la existencia de una ley no depende de puros aspectos formales para que sea válida, sino de argumentos racionales $y$, en última instancia, morales o éticos para que ésta exista. De este modo, el soporte moral de las leyes se lo da, como lo hemos visto, la cabal comprensión del derecho natural, y no el apelo a un puro argumento axiológico sin más.

\section{EL DERECHO NATURAL ASEGURA LA CREACIÓN DE UN MEJOR DERECHO}

La segunda tesis que explica el profesor argentino se refiere al papel que puede llegar a jugar la moral en la creación del derecho. El argumento central es que el apelo a la moral, de algún modo asegura la creación de un mejor derecho. En este punto habrá que establecer que el argumento del mejor derecho posible se refiere a un dere-

10 Tomás de Aquino, Summa Tehologiae, I-II, q. 90, a 2.

11 Ibidem, a. 4. 


\section{¿DERECHO NATURAL O MORAL? COMENTARIOS CRÍTICOS...}

cho "justo", "racionalmente justificado", de modo que la propuesta de Vigo apostaría por afirmar que se alcanzaría el mejor derecho posible si se tomara en cuenta una moral racional.

El argumento clave (no el único) que Vigo utiliza para justificar su pretensión es el apelo a la razón práctica que diferentes autores contemporáneos han rehabilitado y la cual, según el profesor argentino, brindaría definiciones sobre el bien humano a considerar por aquel que tiene la facultad de hacer el derecho. No tomar en cuenta dicha razón práctica implicaría que argumentos jurídicos como los derechos humanos, o cualquier otra juridicidad indisponible se convirtieran en simples edictos de tolerancia revocables, como repite Vigo citando a Spaemann. Y termina el profesor argentino estableciendo: "Al hablar de racionalidad práctica en el momento creativo del derecho, incluimos exigencias de procedimiento o forma, pero también exigencias vinculadas al contenido de lo que se va a crear derecho".

Con las afirmaciones anteriores, Vigo está defendiendo la tesis de que en la creación del derecho o de las leyes, el argumento moral juega un papel relevante, no sólo en los aspectos formales o procedimentales, sino fundamental y principalmente en las cuestiones relativas al contenido de éstas.

Al respecto habrá que decir que la tesis propuesta por Vigo en este punto es una continuación de lo señalado en el punto anterior, pues en algún sentido se está refiriendo a la propia existencia de la norma jurídica. Considerando esto, hemos de señalar que también en este segundo razonamiento el derecho natural ha abonado mucho en explicar que el derecho no sólo debe ser creado conforme a ciertas reglas de procedimiento, sino sobre todo, y particularmente, ha insistido en la idea de que éste no puede dejar de lado su contenido.

En primer lugar, conviene señalar un punto que si bien deja enunciado Vigo, no lo explicita suficientemente, es el relativo a la capacidad o facultad humana que crea la ley. Tal y como ya lo adelantábamos en el argumento anterior es necesario cuestionarse: ¿el derecho es creado por la razón o por voluntad? ¿Qué papel juegan ambas capacidades humanas en la generación de las relaciones jurídicas? ¿Cuál es la respuesta que ofrecería el positivismo jurídico y el iusnaturalismo al respecto? 
Para responder a las preguntas anteriores se debe acudir a quien primero planteó las tesis centrales del positivismo jurídico como fue Hobbes, el cual al definir la ley civil dirá que ésta no es otra cosa que la voluntad del soberano. ${ }^{12}$ Fue esta la misma tesis que sostuvo Austin, ${ }^{13}$ y aunque con algunos matices, fue también la que siempre defendió Kelsen, al señalar que es el acto volitivo la causa creadora de la norma, siendo ésta el sentido objetivo del acto de voluntad. ${ }^{14}$

¿Qué plantea esta posición voluntarista de cara a la producción del derecho? La respuesta es por demás clara: si es la voluntad y no la razón la instancia creadora del derecho, si ésta poco puede decir en la generación del mismo, se deja abierto el camino para que dicha voluntad sea la que determine el contenido de la norma, el cual puede ser cualquiera, el que convenga, el que mejor plazca, o el que en cuestión necesite el soberano de turno, y esto es así porque el parámetro de racionalidad exigido queda al arbitrio de dicho acto de voluntad, es decir, de las puras órdenes y fuerzas. En este punto, como en muchos otros, Kelsen fue especialmente consecuente al determinar: "una norma puede ser tenida por válida aun cuando contradiga al orden moral". ${ }^{15}$ Y cuando fue cuestionado sobre el derecho del régimen dictatorial nazi dirá: "Desde el punto de vista de la ciencia del derecho, el derecho durante la dominación nazi fue derecho. Podemos lamentarlo, pero no negar que fue derecho". ${ }^{16}$

El sendero seguido por el derecho natural clásico es distinto, pero antes de explicar cuál fue éste es conveniente recordar lo que igualmente es tradición clásica, esto es, que un acto libre está regido por dos potencias o capacidades humanas: la inteligencia o razón y la voluntad. De modo que cualquier acción humana que se precie de

12 Cfr. Hobbes, Thomas, Leviatan, México, Fondo de Cultura Económica, 1994, p. 217.

${ }^{13}$ Cfr. Austin, John, Sobre la utilidad del estudio de la jurisprudencia, Nacional, México, 1974, p. 27.

${ }_{14}$ Cfr. Kelsen, Hans, Teoría pura del derecho..., op. cit., p. 18, entre otros muchos lugares.

15 Ibidem, p. 81.

16 Citado por Garzón Valdés, Ernesto (comp.), "Introducción", Derecho y Filosofía, 3a. ed., México, Fontamara, 1999, p. 8. 
¿DERECHO NATURAL O MORAL? COMENTARIOS CRÍTICOS...

ser libre debe ser un acto racional y voluntario. ${ }^{17}$ Esto es importante recordarlo porque en diferentes lugares de su monumental obra Tomás de Aquino reflexionará acerca este tema, es decir, sobre si la ley es producto de la razón o de la voluntad. Dirá al respecto el doctor angélico que a la ley le compete mandar y prohibir, y siendo esto un acto de imperio, entonces dicho acto es propio de la razón, luego "la ley es producto de la razón", ${ }^{18}$ o "Sígase, pues, que la ley es algo que pertenece a la razón". ${ }^{19}$

Sin embargo, también habrá que aclarar que para la tradición del derecho natural lo anterior no es todo. El Aquinate nos enseñó que no bastaba la razón o inteligencia para instituir la ley, sino que era preciso que esta facultad intelectiva fuera acompañada de la voluntad del gobernante. Así, en la Summa Tehologiae, I-II, q. 95, a. 4, al estar hablando de la ley humana afirmará lo más claramente posible que "es esencia de la ley... que emane de quien gobierna el Estado". ${ }^{20}$

De este modo, la creación del derecho y de la ley es para el derecho natural clásico una conjunción de ambas potencias o capacidades del hombre, es decir, tiene que ser un acto racional o inteligente, y deber ser además querido por quien gobierna el Estado, es decir producto de la voluntad de éste. Al respecto hay que puntualizar que la razón de la que habla Tomás de Aquino no es una razón instrumental, sino aquella por la que los sistemas jurídicos obtienen su sentido y su forma, sirviendo como parámetro de evaluación para medir su conformidad con el derecho natural. También habrá que aclarar que la voluntad señalada por Aquino no es una voluntad autónoma, sino dependiente de la inteligencia y hasta dócil a los imperativos de la razón que ve y prevé. ${ }^{21}$

En este punto, uno de los autores que mejor ha interpretado el pensamiento tomista ha sido John Finnis, quien afirma al respecto:

17 Cfr. Hervada, Javier, Cuatro lecciones de derecho natural. Parte especial, 3a. ed., Pamplona, Eunsa, 1993, p. 35.

18 Aquino, Tomás de, Summa Tehologiae, I-II, q. 90, a. 1.

19 Idem.

20 Aquino, Tomás de, Summa Tehologiae, I-II, q. 95, a. 4.

21 Graneris, Giuseppe, Contribución tomista a la filosofía del derecho..., cit., p. 34. 
Tomás de Aquino describe la ley humana positiva como hecha por la voluntad (es decir, por la decisión de adoptar un esquema en desmedro de otro u otros). Pero cuando habla precisamente, aduce que la ley es un asunto de la razón antes que de la voluntad; la obligación tiene que ver con los medios requeridos para servir y respetar los fines y principios de la razón práctica; el imperium, por el cual uno, al ejecutar las elecciones propias, se dirige a sí mismo (o, análogamente, como gobernante dirige la propia comunidad) corresponde a la razón antes que a la voluntad..$^{22}$

Ahora bien, para el iusnaturalismo clásico, la concurrencia de ambas facultades humanas en la creación de la ley determinará también las funciones que ésta ha de realizar en sociedad. En este punto, Giuseppe Graneris en su obra Contribución tomista a la filosofía del derecho, ${ }^{23}$ dirá que la ley está llamada a realizar dos oficios: el primero pasivo, formal y racional, y el segundo, activo, eficiente y voluntario.

El papel pasivo de la ley es porque no hace sino transcribir lo que las cosas exigen, adecuando el hombre su conducta a ellas. La función Formal es porque la actividad humana sólo le da forma a una realidad preexistente al acto legislativo, y la función racional es porque la ley es obra de la razón que lee "en las cosas sus relaciones necesarias y expresarlas en fórmulas aptas para constituirse en normas de vida humana". 24

Por lo que al segundo oficio de la ley se refiere, dice Graneris que es activo porque en éste el legislador es capaz de establecer las fórmulas que él mismo dicta e impone. Eficiente, porque en dicha actividad el hombre (legislador) pone algo nuevo plasmando a su modo el orden social, y voluntario "en cuanto la introducción de estos nuevos elementos en el edificio jurídico no es conclusión necesaria de un proceso lógico, sino efecto de una elección libre del legislador". ${ }^{25}$

Que en la creación de la ley participen razón y voluntad nos remite a un segundo argumento, el cual tiene que ver con el ejercicio 207.

22 Finnis, John, Estudios de Teoría del derecho natural, México, UNAM, 2017, p.

23 Graneris, Giuseppe, Contribución tomista a la filosofía del derecho..., cit., p. 34.

24 Ibidem, p. 35.

25 Idem. 


\section{¿DERECHO NATURAL O MORAL? COMENTARIOS CRÍTICOS...}

de la razón práctica y la serie de bienes a los que ésta tiende, los cuales serían, en el contexto que venimos explicando, aquello que es aprehendido por la razón y puesto como contenido de la leyes por la voluntad.

El Aquinate, comentando el tema de la ley natural en el artículo 2 de la cuestión 94 en la I-II, de la Summa Tehologiae, se pregunta si la ley natural ¿comprende muchos preceptos o uno solamente?, respondiendose más adelante que los principios de la ley natural son en el orden práctico lo que los primeros principios en el orden especulativo. Aquí, el Aquinate está tratando ya el tema de la razón práctica, la cual está regida - como la especulativa- por una serie de principios de los cuales el primero es el que se funda sobre la noción de bien, formulándose del siguiente modo: "el bien ha de hacerse y buscarse; el mal ha de evitarse", señalando que sobre este principio se fundan todos los demás preceptos de la ley natural, de suerte que todo cuanto haya de hacerse o evitarse cae bajo los preceptos de esta ley en la medida en que la razón práctica lo capte y aprehenda naturalmente como un bien humano básico. ${ }^{26}$

Se resume entonces que lo aprendido por la razón es aquello que es bueno. El problema ahora radicaría en saber qué se quiere decir con esto, cuál es el significado real de lo bueno, etcétera. El propio Tomás de Aquino responde diciendo que es aquello a lo que el hombre se siente naturalmente inclinado, enumerando a continuación una serie de bienes (bienes humanos básicos), como aquello a lo que los hombres tienden como inclinaciones naturales. ${ }^{27}$ Así, por ejemplo, una primera tendencia natural en el hombre es la que tiene que ver con la conservación de su propio ser, señalando textualmente que "de acuerdo con esta inclinación pertenece a la ley natural todo aquello que ayuda a la conservación de la vida humana e impide su destrucción". 28

En segundo lugar, existe una inclinación del hombre a bienes más específicos, más determinados, tales como la conjunción de los se-

26 Cfr. Tomás de Aquino, Summa Tehologiae, I-II, q. 94 a. 2.

27 Dice Tomás de Aquino "De aquí que el orden de los preceptos de la ley natural sea correlativo al orden de las inclinaciones naturales". Ibidem.

28 Idem. 
xos, siendo esto un bien humano que ayuda a la familia a través del matrimonio. En el mismo sentido, Tomás de Aquino también establece como un bien aprehendido la inclinación natural del hombre a la educación de sus hijos, etcétera. ${ }^{29}$

En tercer lugar, el Aquinate señala que existe otra inclinación natural en el hombre a aquello que lo hace realmente humano, como es la inclinación a la búsqueda de la verdad acerca de Dios y a vivir en sociedad. ${ }^{30}$ Con esto dirá que corresponde a la tercera inclinación todo aquello que tiende a evitar la ignorancia, respetar a los conciudadanos y lo demás relacionado con este bien humano. ${ }^{31}$

En conclusión, la existencia de estos bienes humanos descritos por Santo Tomás es previa a la ley positiva y a todo acuerdo y consenso entre los hombres, encontrándose atribuidos — dichos bienes - a las personas y teniendo como título su naturaleza humana; son, en definitiva, lo suyo de cada uno, es decir, los criterios de justicia que han de ser tomados en cuenta a la hora de la creación de las leyes que integrarán después los sistemas normativos.

Con esto queda claro entonces que el apelo a la moral racional para crear el mejor derecho posible es innecesaria, porque los argumentos que muestra el derecho natural son suficientes para entender que el derecho y su creación es un asunto de la razón que busca la consecución de ciertos bienes humanos.

Una última cuestión nos quedaría por resolver en el tema de la creación de las leyes, esta tiene que ver con los aspectos formales, más específicamente procedimentales de la elaboración de éstas. En rigor, lo que hay que decir es que ni Aristóteles ni Tomás de Aquino pensaron en un procedimiento legislativo como lo pensamos ahora nosotros, ellos idearon sus razonamientos en forma general para cualquiera que tuviera la potestad de crear leyes, aunque no han faltado empeños contemporáneos que hablen de un "derecho natural procesal" $^{32}$

29 Idem.

30 Idem.

31 Idem.

32 Cfr. Fuller, L. Lon, The Morality of Law, U.S.A, Yale University, 1964, trad. Cast. F. Navarro, La moral del derecho, México, Trillas, 1967, pp. 56-107. 
¿DERECHO NATURAL O MORAL? COMENTARIOS CRÍTICOS...

\section{EL DERECHO NATURAL COMO ELEMENTO GARANTIZADOR DE LA MEJOR APLICACIÓN DEL DERECHO}

El tercer argumento que expone Rodolfo Vigo se refiere al papel que la moral juega en la aplicación del derecho, remitiéndonos con esto al que sin duda es el protagonista de dicha labor, es decir, el juez. El profesor argentino comienza recordándonos cuál ha sido la labor asignada a este personaje en el positivismo jurídico, señalando cómo a partir del siglo XVIII su trabajo consistió en identificar fundamentalmente la norma jurídica aplicable al caso que tenía que resolver; reconstruir dicho asunto y, a través de un ejercicio de subsunción, aplicar dicha norma a tal problema. La labor mecánica del juzgador nos la había dejado para la historia Montesquieu al señalar que los jueces de la nación no eran más que instrumentos que sólo podían pronunciar las palabras de la ley, "seres inanimados· llegó a sentenciar. $^{33}$

Pero quien representaría de mejor manera la actitud pétrea del juzgador en el positivismo jurídico fue Kelsen, quien refiriéndose a la labor por antonomacia que el juez está llamado a realizar como es la interpretación jurídica hará ver que ésta, igual que la norma jurídica, no es otra cosa que un acto de voluntad. Dirá el profesor austríaco: "Por ello el alcanzar una norma individual a través del proceso de aplicación de la ley, es, en tanto se cumple dentro del marco de la norma general, una función volitiva". ${ }^{34}$

Al hilo de la exposición que realiza Vigo, va mostrando también cuáles son las nuevas aportaciones y argumentaciones teóricas con las que cuenta el juez de hoy y que son ofrecidas por la más influyente filosofía y teoría del derecho. Así, expone sucintamente la famosa discusión dada en la década de los sesenta y setenta sobre el empleo

33 Montesquieu, Del espíritu de las leyes, 4a. ed., Madrid, Tecnos, 1998, p. 112.

34 Kelsen, Hans, Teoría pura del derecho..., cit., p. 353-354. En un sentido análogo Bobbio reconocerá la actitud pétrea realizada por el juzgador: "Al positivismo jurídico se le acusa de mantener una concepción estática de la interpretación, que debería consistir sólo en una reconstrucción precisa de la voluntad subjetiva del legislador que ha establecido las normas...". Bobbio, Norberto, El positivismo jurídico, Madrid, Debate, 1993, p. 217. 
de "reglas" y "principios" por parte de los jueces, haciendo ver la relevante utilidad que estos últimos tienen en la labor jurisprudencial. Igualmente, reseña la tan repetida tesis alemana de mediados del siglo XX sobre la rehabilitación de la razón práctica en el ámbito jurídico, la cual se expresa a través de diferentes razonamientos, por ejemplo, por medio de la argumentación jurídica. Esta última materia es impulsada por diferentes pensadores cuya agenda como dice Vigo "tiene amplias coincidencias con tesis iusnaturalistas". ${ }^{35}$

Finalmente, para justificar su tesis central acude a la enunciación de una de las virtudes más importantes en la toma de decisiones jurídicas cómo es la virtud de la prudencia que, como se nos ha enseñado desde antiguo, sirve para discernir lo bueno de lo malo, en aras del bien vivir en general. Termina diciendo el profesor argentino lo siguiente: "El juicio prudencial constituye una especie de puente entre aquellas exigencias generales, que por ejemplo establece la ley, y las circunstancias contingentes de los problemas que corresponde resolver".

En rigor no le falta razón al profesor argentino cuando señala que la consideración de la prudencia - comprendida como virtud moral- ayuda a la hora de concretar y aplicar el derecho, garantizándonos de algún modo una mejor y correcta aplicación del mismo. Sin embargo, esta virtud no sólo tiene una faceta moral, tiene también, y quizá de manera más significativa, un rostro eminentemente jurídico y más específicamente una clara ascendencia y presentación iusnaturalista. Este patrimonio iusnaturalista se expresa -entre otros- principalmente a través de dos argumentos: i) por una parte, la comprensión cabal de lo que significa el oficio del jurista, específicamente el juez, y, por la otra, ii) la concurrencia de la virtud de la prudencia con otras virtudes específicamente jurídicas como la justicia.

Quien fuera uno de los iusnaturalistas más importantes del siglo XX, como fue el profesor Javier Hervada, señalará que la perspectiva central desde donde ha de explicarse el derecho y por tanto el derecho natural, es la perspectiva del foro, el derecho en acción. Dice

35 Cfr. Atienza, Manuel, El derecho como argumentación, Barcelona, Ariel, 2006, p. 45 . 
el profesor español: "El oficio del jurista es un arte o ciencia práctica... es un saber, que comporta discernir: el discernimiento de lo justo y de lo injusto, el discernimiento del derecho y de la lesión del derecho....".36

En este contexto, el jurista por antonomasia en la vida práctica del derecho, es decir, en la vida del foro, es el juez. Esto no quiere decir que se desestime la labor que realizan otros operadores del derecho, pero será el juez quién esté llamado —desde la prudencia- a determinar lo que es suyo de cada cual, esto es, la justicia. El jurista - dice Hervada-

declara el derecho: el juez sentencia acerca de cuál es el derecho en el caso concreto, el abogado alega lo que entiende ser el derecho de su cliente, el letrado manifiesta el derecho. En eso consiste ser jurista: en la iuris dictio, en la declaración del derecho, en discernir y pronunciar la sentencia que contiene el derecho, lo que es justo. ${ }^{37}$

En esto consiste el oficio de ser jurista.

Para precisar aún más lo anterior, se ha de señalar que el propio Hervada reconoce que este arte de discernir lo justo parte de un presupuesto básico, este es, que las cosas (bienes) están repartidas, es decir, que se encuentran atribuidas a alguien según un título y medida a las personas en una relación de suidad. ${ }^{38}$ Ahora bien, el arte de decir lo justo por parte del juez se da cuando esa relación de suidad se rompe, es decir, cuando las cosas pueden estar en poder de otro, o ser dañadas o perdidas, o robadas, exigiendo al juzgador el respeto y restitución de esas cosas a sus titulares. A partir de aquí puede entenderse entonces como la labor del juez es la reparación de la relación rota, introduciendo en consecuencia el acto de justicia. $^{39}$

36 Hervada, Javier, Lecciones propedéuticas de filosofía de derecho, Pamplona, Eunsa, 1992, p. 75.

37 Ibidem.

38 Cfr. Hervada, Javier, Introducción crítica al derecho natural, 7a. ed., Pamplona, Eunsa, pp. 23-31.

39 Cfr. ibidem, pp. 31-46. 
Que la labor esencial del juzgador sea la determinación o concreción de la justicia nos remite previamente a una comprensión general de la prudencia, dado que, como dice Gómez Robledo, el ejercicio de una virtud entraña en el fondo el ejercicio del resto de las virtudes. ${ }^{40}$ Para el caso específico, el cultivo de la virtud de la justicia tiene como acto antecedente inmediato el ejercicio de la prudencia, particularmente la prudencia judicial. Así, el oficio del juez al que nos hemos referido antes, se traduce en el ejercicio público de un saber prudente, presentándose así como la primera de las virtudes que ha de poseer el juzgador.

La virtud de la prudencia ha sido objeto de estudio de la larga tradición iusnaturalista encabezada por Aristóteles y continuada después por Tomás de Aquino a quién debemos, sin duda, habernos heredado por primera vez un tratado general sobre esta virtud. Refiriéndose a la prudencia, el Estagirita deja establecidas las bases de lo que después entenderemos por prudencia en general, señalando, desde el siglo IV a. C., en qué consiste esta virtud. Nos dice Aristóteles: “...La prudencia, entonces, es por necesidad un modo de ser racional, verdadero y práctico, respecto de lo que es bueno para el hombre". ${ }^{41}$ La prudencia es, en definitiva, un ejercicio de deliberación sobre lo bueno y conveniente para el hombre, pero no en un sentido parcial o de interés particular, sino para el bien vivir de éste en general, es decir, para el bien vivir del hombre en sociedad. ${ }^{42}$

Confirma lo antes señalado el propio Tomás de Aquino, quien en la Summa Teohologiae, II-II, cuestión 47, en el artículo 4, se pregunta sobre si la prudencia es virtud, señalando posteriormente que efectivamente lo es, y reforzando la tesis de que esta virtud hace bueno al sujeto que la posee, pero también los actos que realiza: "A la prudencia atañe la aplicación de la recta razón a obrar, cosa que no se hace sin la rectificación de la voluntad. De ahí que la prudencia tiene no solamente la esencia de la virtud, como las demás virtudes intelectuales, sino también la noción de virtud propia de las virtu-

40 Cfr. Gómez Robledo, Antonio, Ensayo sobre las virtudes intelectuales, México, Fondo de Cultura Económica, 1996, pp. 202-208.

41 Aristóteles, Ética nicomáquea, VI, c. 5, 1140b-20.

42 Cfr. idem. 
des morales, entre las cuales se enumera".43 La prudencia entonces participa del mundo teórico como del práctico, teniendo como fin último el bien humano, es así que la prudencia es una virtud intelectual, pero también es virtud del correcto obrar moral. Ambos caracteres de la prudencia la colocan en íntima relación con la justicia.

Prudencia y justicia por tanto son así las virtudes más importantes de la labor judicial. ¿Qué justicia? La justicia que está llamado a concretar el juzgador no es otra que la establecida en el Digesto 1.1.10, la cual es recogida por Tomás de Aquino, quien tendrá el gran mérito de haberla perfeccionado estableciendo que ésta es un hábito virtuoso que atañe a la voluntad, que es un querer conforme con la razón y por tanto que siempre es hecha con conciencia y libertad.

Nominalmente, la definición de lo que justicia es en Tomás de Aquino será entonces la siguiente: "El hábito según el cual uno, con constante y perpetua voluntad, da a cada uno su derecho"..4 Siendo la justicia una virtud que ordena al hombre en las cosas que están en relación con otro, dicha relación implica una cierta igualdad, esta igualdad es siempre proporcional o analógica, como lo deja establecido en el artículo 2 cuestión 58 de la II-II de la Summa Tehologiae. De este modo, la idea de igualdad está en el centro de la definición de justicia del Aquinate, porque la misma será la condición de dos tipos de justicia, a saber, la conmutativa y la distributiva.

Para el derecho natural entonces, el juez no es sólo la figura más importante del derecho por la facultad decisoria que tiene, sino porque se exige de él una aplicación del derecho prudente y justa, no sólo la aplicación de la ley. Así, la ciencia que el juez ha de cultivar no es la ciencia de lo legal, sino la ciencia de la determinación de lo justo. Con un buen juez, comprometido con la prudencia y la justicia, el derecho natural, antes que la moral, asegura la mejor aplicación del derecho. 


\section{EL DERECHO NATURAL COMO BASE \\ DE UN MEJOR CONOCIMIENTO DEL DERECHO}

Un cuarto argumento que explica Rodolfo Vigo se refiere al tema espistemológico del derecho, considerando que el apelo a la moral puede ayudar a un mejor conocimiento del mismo. Como es su costumbre, comienza narrando cuál fue el escenario anterior a la Modernidad y después de ésta, señalando que lo que antes fue calificado como conocimiento filosófico hoy se llama científico, adquiriendo con este nuevo nombre el estatus de verdadero. Los tiempos modernos impusieron la idea de que para llegar a esta categoría, tal conocimiento debía ser elaborado bajo los parámetros de la ciencia moderna, es decir, al estilo more geométrico. ${ }^{45}$

Sin embargo, la palabra ciencia puede entenderse hoy al menos en dos sentidos: el clásico y el moderno. El primero entiende a ésta como el conocimiento racional de todas las cosas por sus causas últimas, siendo este sentido de la ciencia el identificado con el pensar filosófico en su sentido más amplio. ${ }^{46}$ Por su parte el significado moderno de la ciencia se caracterizaría por ser principalmente un conocimiento fenoménico y positivo. ${ }^{47}$ Este último es el que en los tiempos contemporáneos ha prevalecido, y ha sido, sin duda el que autores iuspositivistas han asumido en sus explicaciones jurídicas. Así, por ejemplo, Hans Kelsen, como sabemos, pretendió desarrollar una teoría jurídica "purificada de toda ideología política y de todo elemento científico-natural". ${ }^{48}$

Continúa Vigo señalando que este modo de hacer ciencia ha venido a ser modificado por las más recientes contribuciones en la teoría jurídica contemporánea, poniendo como ejemplo las aportaciones del profesor alemán Robert Alexy, quien, como sabemos, es uno

45 Nos dice Jesús Ballesteros al respecto que el positivismo como corriente filosófica moderna fue un conocimiento que se caracterizaría por la consideración de la filosofía como acilla scientiae, o en otros términos que preconiza el predominio del pensar calculante, o la razón instrumental. Cfr. Ballesteros, Jesús, Sobre el sentido del derecho, 2a. ed., Madrid, Tecnos, 1986, p. 19.

46 Cfr. Hervada, Javier, Lecciones propedéuticas de filosofía de derecho..., cit., p. 8.

47 Cfr. ibidem, p. 10.

48 Kelsen, Hans, Teoría pura del derecho, cit., p. 7. 
¿DERECHO NATURAL O MORAL? COMENTARIOS CRÍTICOS...

de los autores que más ha cuestionado ese modo de hacer ciencia a través de su tesis de la razón práctica. Luego de describir las diferentes etapas y los distintos argumentos que Alexy ha desarrollado a lo largo de su obra, termina señalando algo en lo que hoy prácticamente todos coincidiríamos, a saber, las partes que integrarían la filosofía del derecho y el conocimiento del mismo, a saber: i) el problema ontológico del derecho; ii) el problema gnoseológico jurídico; iii) el problema lógico, y iv) el problema axiológico. Ninguna propuesta que pretenda dar cuenta del conocimiento jurídico podrá prescindir de tales rubros.

Ahora ¿necesitamos de la moral para tener un conocimiento más amplio y por tanto mejor justificado del derecho? Probablemente la perspectiva que Vigo trata de rescatar de Alexy se refiera al reconocimiento de una validez moral o valorativa del derecho, la cual, sin perder de vista su racionalidad, posibilitaría contar con un mejor conocimiento de la realidad jurídica y, por tanto, a ser considerado igualmente científico. Si este es argumento que desea proponer Vigo no le falta razón, incorporar ese otro elemento en el conocimiento del derecho nos ofrece de éste una perspectiva mucho más amplia a la ofrecida por otras propuestas jurídicas como la iuspositivista. Esto ya lo hemos destacado en renglones precedentes. Sin embargo, hay otro razonamiento que sin ser el que necesariamente querría ofrecer Vigo, vale la pena explicar de manera breve por la importancia del tema, este es, el relativo al carácter científico del derecho natural clásico.

Es innegable que uno de los más importantes temas en el análisis y explicación del derecho es la calificación científica de éste, y este propósito lo mismo ha sido objeto de preocupación por parte de iusnaturalistas que de iuspositivista. Así, casi todas las corrientes del pensamiento jurídico se han esforzado por darle ese cariz a sus explicaciones jurídicas. A todo esto hay que decir que no han faltado quienes han utilizado dicho argumento para descalificar al derecho natural, considerando que éste y su apelo a argumentos metafísicos y valorativos, lo inhabilitan para ser considerado científico. ${ }^{49}$ ¿Man-

49 Cfr. Kelsen, Hans, La idea del derecho natural y otros ensayos, México, Nacional, 1974, pp. 15 y 16. 
tiene el derecho natural todo un aparato gnoseológico que permita calificarlo como científico? ¿Existe una ciencia del derecho natural, o este calificativo corresponde sólo a una visión normativista del derecho?

Sobre lo anterior, lo primero que tendríamos que decir es que si ha existido un argumento que más desvelo ha causado a los pensadores iusnaturalistas ha sido precisamente dar cuenta del carácter científico del derecho natural. Con bastante autoridad puede decirse que no hay trabajo de iusnaturalista serio que no se haya ocupado de esta particular cuestión. ${ }^{50}$

¿Es posible entender el derecho natural desde el punto de vista científico? Sin duda, la respuesta no puede ser otra que confirmar que el derecho natural es un saber científico, el cual es caracterizado porque posee un conjunto de conocimientos ciertos, generales y sistemáticos, obtenidos a través de un método riguroso. ${ }^{51}$ De ahí que pensadores tan autorizados como Javier Hervada, a quien seguimos en esta parte del trabajo, hablen rigurosamente de una ciencia del derecho natural.

La estructura y contenido de la ciencia del derecho natural de la que habla Hervada la divide en dos grandes apartados. En primer lugar, dicha ciencia debe distinguirse tanto de la filosofía del derecho como de las diferentes ramas de la ciencia jurídica. Así, la ciencia del derecho natural estudia el quid iuris, es decir, "los diversos factores naturales del derecho vigente y por tanto los factores naturales del orden jurídico en relación con su realización práctica". ${ }^{52}$ Esta parte estudia lo que se encuentra como lo justo natural en cada una de las

50 Entre otros muchos trabajos, cfr. Martínez Doral, José María, La estructura del conocimiento jurídico, Universidad de Navarra, Pamplona, 1963, passim; Hervada, Javier, Lecciones propedéuticas de filosofía de derecho..., cit., pp. 1-56, y 531-636. Del mismo autor, Introducción crítica al derecho natural, cit., pp. 189-195. Cfr. Preciado, Hernández, Rafael, Lecciones de filosofía del derecho, México, UNAM, 1986, pp. 10 62; Orrego Sánchez, Cristóbal, Analítica del derecho justo. La crisis del positivismo jurídico y la crítica del derecho natural, México, UNAM, 2005, pp. 7-54; Quintana, Martín, Eduardo, Notas sobre el derecho natural en el iusnaturalismo, Buenos Aires, Educa, 2008, pp. 111-162.

51 Cfr. Hervada, Javier, Lecciones propedéuticas de filosofía de derecho..., cit., p. 11.

52 Hervada, Javier, Introducción crítica al derecho natural..., cit., p. 191. 
materias en las que se divide el derecho vigente, el derecho con el que se opera en la vida práctica.

Lo anterior significa que la ciencia del derecho natural se distingue del resto de las ciencias jurídicas no porque sea una rama autónoma, sino porque dicha ciencia se ciñe sólo a lo «justo natural» de tales ciencias, estando limitada por su respectiva materia. Sin embargo, comparte con el resto de las ciencias jurídicas su finalidad, es decir, ser una disciplina práctica, las que deben "conocer, sintetizar y armonizar lo natural y lo positivo". ${ }^{33}$ Así, si tomáramos como ejemplo el derecho que rige las relaciones laborales, dice Quintana Martín, reconoceríamos en estas lo justo natural en aquello que de natural tienen tales relaciones como puede ser: que el salario sea el adecuado considerando la dignidad del trabajador; si en el lugar de trabajo existen las condiciones de seguridad e higiene necesarias; si hay una adecuada protección social; si el trabajador contará con un seguro de vejez cuando se retire, etcétera. ${ }^{54}$ Otro ejemplo sería el conjunto de relaciones que rigen una ciencia del derecho familiar, lo natural de esta ciencia sería aquello por lo que dicha institución se funda y que va desde la protección del derecho a la vida, hasta el régimen de sucesiones, pasando, claro está, por el matrimonio, el régimen de obligaciones paternales y filiales, el régimen de bienes, etcétera. ${ }^{55}$

Lo segundo que caracteriza a la ciencia del derecho natural es el objeto. Así, el objeto principal de la ciencia del derecho natural es la exposición del sistema de derechos naturales, o conjunto de lo justo natural. ${ }^{56}$ Aquí — como dice Hervada- el núcleo fundamental es esta parte especial, que consiste en la exposición de ese sistema de derechos, los cuales, para ser explicados y comprendidos deben tener como precedente una parte general, donde se estudiaría la noción, el método y la evolución histórica de esta ciencia. ${ }^{57}$

$53 \quad$ Ibidem, p. 192.

54 Cfr. Quintana, Martín, Eduardo, Notas sobre el derecho natural..., cit., p. 138.

55 Cfr. idem.

56 Cfr. Hervada, Javier, Introducción crítica al derecho natural..., cit., p. 193.

57 Idem. 
En este punto es importante distinguir el objeto material y el objeto formal del derecho natural, los cuales son materia de estudio de la ciencia del derecho natural. El objeto material de este derecho es la misma cosa justa, y por justo entendemos tanto las cosas como las acciones. ${ }^{58}$ Así, lo que le da el carácter de jurídico al derecho es que esas cosas o acciones son justas en tanto que son debidas a otro. Por su parte, el objeto formal del derecho natural es la justicia como un acto segundo, por la cual se entrega, restituye, devuelve, etcétera, cuando esa relación de debitud o deuda se ha roto.

Con lo señalado anteriormente queda claro que el derecho natural y la ciencia que lo estudia no es - como falsamente reseñan sus detractores - un especie de ideal, sino que como todo derecho y toda ciencia que lo estudia, es un conocimiento de lo real. La ciencia del derecho natural, por tanto, está arraigada en la vida práctica del derecho, en la vida real, no teniendo como fundamento cualquier metafísica, sino una metafísica del ser. De este modo, la ciencia del derecho natural es esencial y fundamentalmente una ciencia práctica, la cual está llamada a la acción; pero como hemos dicho más arriba, el hecho de que sea una disciplina de lo operable basada en la razón práctica, no quiere decir que se encuentre separada de la razón especulativa. ${ }^{59}$ De este modo, el entendimiento en cuanto dirige la acción se llama práctico perfeccionándose con el arte y la prudencia.

Finalmente, consideraremos un último rasgo de la ciencia del derecho natural, es el que tiene que ver con su método, el cual ha sido

58 Tomás de Aquino, Summa Tehologiae, II-II, q. 57. a. 2. Cfr. Quintana, Martín, Eduardo, Notas sobre el derecho natural en el..., cit., p. 130.

59 Dice Eduardo Martín Quintana: "La ciencia práctica, si bien tiene por objeto un operable y es práctica por su finalidad, pues conoce para obrar, conoce de modo teórico o explicativo y considera el universo de obrar humano y de los valores desde el punto de vista de la naturaleza del hombre y su finalidad. En este orden los fines desempeñan la función de los principios de la ciencia teórica

La diferencia entre el conocimiento especulativamente-práctico, propio de la ciencia moral y de la jurídica y el práctico-práctico, propio de la prudencia, radica en que el primero se dirige a conocer lo bueno y conveniente como verdadero, únicamente para conocerlo pero no para ponerlo en acción, mientras que el segundo conoce para obrar operativamente, por ejemplo, el juez que conoce las circunstancias de litigio para dictar sentencia”. Quintana, Martín, Eduardo, Notas sobre el derecho natural..., cit., p. 136. 
objeto de múltiples esfuerzos. Así, por ejemplo, Martín Quintana señala cinco características del método jurídico en el iusnaturalismo clásico: a) problemático o aporético, el cual reconoce que nuestras acciones tienen carácter contingente y ante un problema hemos de tomar una decisión entre distintas alternativas hasta llegar a aquella que nos ofrezca mejores visos de prudencia; b) dialéctico, es decir, que implica siempre una relación con otro; c) sintético, que va de las partes al todo; d) deliberativo, en donde la respuesta es, casi siempre, fruto de una deliberación; e) valorativo, es decir, cualquier respuesta a nuestros problemas tendrá siempre una calificación moral de valioso o disvalioso. ${ }^{60}$

\section{EL DERECHO NATURAL COMO LÍMITE \\ AL CUMPLIMIENTO DE LA NORMA JURÍDICA}

Uno de los más importantes temas tratados en este quinto argumento por el profesor Vigo se refiere al asunto - siempre espinoso - de la obediencia a la ley injusta. Para el positivismo jurídico este argumento no representa un problema relevante dado que desde esta posición sería impensable imaginarnos la posibilidad de incumplir la ley invocando la conciencia personal por el daño que, eventualmente, pudiera traer su incumplimiento.

A lo que se está refiriendo Vigo es al discutido tema de la objeción de conciencia en el derecho. Así lo reconoce el propio profesor argentino al señalar:

...estimamos que un complemento ineludible del análisis de la ley injusta es el derecho a la objeción de conciencia que cubre cierto incumplimiento de la norma jurídica en función de razones morales racionales que puede invocar su destinatario. Ese derecho, cubre los reparos razonables del ciudadano o funcionario frente a la violencia moral que le provoca la prescripción en cuestión, y así el derecho como institución se pone al servicio de un auténtico bien común que incluye bienes personales.

$60 \quad$ Ibidem, p. 152. 
La objeción de conciencia dentro de las filas del iusnaturalismo y aún en corrientes diferentes a ésta no convoca unanimidad. Así, por ejemplo, pensadores tan renombrados como John Finnis reconocen la obligación moral prima facie de obedecer al derecho, y que las reglas jurídicas gozan de una fuerza excluyente - como cita el profesor argentino-. Por otra parte, autores no iusnaturalistas como Carlos Santiago Nino, aceptaron, según Vigo, "no suscribir ninguna obligación absoluta de obedecer al derecho", suscribiendo la objeción de conciencia, y más aún, la desobediencia civil.

¿El apelo a la moral o las convicciones éticas, puede dar lugar a una desobediencia de las obligaciones legales tal y como propone la objeción de conciencia? ¿Qué respuesta es la que ofrece el derecho natural clásico ante el tema de las leyes injustas y de la desobediencia las mismas? ${ }^{61}$

Las respuestas a la problemática de la objeción de conciencia son planteadas desde diferentes argumentos, los cuales vale la pena destacar aunque sea en forma breve. Centraremos nuestra atención en al menos dos razonamientos especialmente significativos. El primero consistirá en comprobar si efectivamente en el iusnaturalismo clásico, y particularmente en Tomás de Aquino, podemos encontrar expresamente mencionada la tesis Lex injusta non est lex. El segundo punto consistiría en precisar los alcances jurídicos y morales de dicha expresión, específicamente convendría aclarar si el iusnaturalismo clásico exige obediencia a las leyes injustas. Con esto podríamos dilucidar si es la moral o el derecho natural, quien plantea mejores respuestas a la observancia o no de las leyes injustas.

Como se señaló en renglones precedentes, uno de los argumentos más fuertemente discutidos en la filosofía del derecho, y particularmente en la razón práctica, es el tema de si una norma injusta es ley o no lo es. De ahí se deriva el argumento de que si lo es, entonces debe ser obedecida, y en el supuesto de que no sea así, cabría la po-

61 Para un análisis detallado del derecho de objeción de conciencia cfr. Patiño Reyes, Alberto, La objeción de conciencia ante el derecho mexicano. ¿Incumplimiento del deber jurídico o libre ejercicio de un derecho humano?,México, Tiran Lo Blanch, 2021, passim. 
sibilidad de no obedecerla. Este es el quit de la objeción de conciencia, y por eso es importante destacarlo en este punto.

Han sido muchos los teóricos que erróneamente han atribuido al iusnaturalismo clásico la tesis de afirmar que una ley injusta no es ley (Lex injusta non est lex). Uno de estos autores fue Hart, quien atribuye expresamente al derecho natural, al pensamiento escolástico y al mismo Tomás de Aquino, dicho razonamiento. Al principio de El concepto de derecho dice el profesor inglés lo siguiente: "Así, la afirmación de que «una norma jurídica injusta no es una norma jurídica suena» tanto a exageración y a paradoja, sino a falsedad...." ${ }^{62}$

Aunque Hart atribuye esta afirmación a San Agustín, lo cierto es que menciona expresamente a Tomás de Aquino, es decir, al segundo autor más importante del iusnaturalismo clásico. Ante tan confiada afirmación la pregunta que conviene formularse es: ¿podemos encontrar dicho argumento en la obra del Aquinate como lo señala Hart? La respuesta es no. Pensadores bastante autorizados dirán que la expresión Lex injusta non est Lex no puede ser hallada como referencia expresa en los más importantes pensadores iusnaturalistas clásicos. ${ }^{63}$ Estos mismos autores señalan que sí puede encontarse alguna referencia a dicha tesis, pero este hallazgo ni es igual al que señala Hart, ni tampoco debe ser hecho sin matizaciones, implicando así una mayor complejidad que la que se pretende atribuir a la misma. ${ }^{64}$

Si se analiza con detenimiento la obra de Tomás de Aquino no se va a localizar ni una sola vez el referido texto. ${ }^{65}$ Lo que, en todo caso, es posible reconocer, es la recreación que el Aquinate hace a una cita textualmente incompleta de San Agustín en libero arbitrio, según la cual no pareciera que fuera ley la que no es justa. ${ }^{66}$

62 Hart, H. L. A., El concepto de derecho, trad. de Genaro R. Carrió, 2a. ed., Buenos Aires, Abeledo-Perrot, 1995, p. 9.

63 Cfr. Massini, Correas, Carlos, I., y García-Huidobro, Joaquín, "Valoración e inclusión en el derecho". La máxima "Lex injusta non est Lex" y la iusfilosofía contemporánea", en varios autores, Razón jurídica y razón moral. Estudio sobre la valoración ética en el derecho, México, Porrúa-U. Austral, 2012, p. 121.

${ }_{64}$ Cfr. idem.
${ }_{65}$ Cfr. idem.
${ }_{66}$ Cfr. idem. 
Algunos otros lugares dónde Tomás de Aquino se refiere al tema en cuestión son, por ejemplo, en la Summa Tehologiae, I-II, cuestión 95, artículo 2, c, cuando se pregunta si acaso toda ley positiva deriva de la ley natural, estableciendo en su parte conducente lo siguiente:

Ahora bien, en los asuntos humanos se dice que una cosa es justa cuando es recta en función de la regla de la razón. Mas la primera regla de la razón es la ley natural, como ya vimos (q. 91 a. 2, ad 2). Luego la ley positiva humana en tanto tiene fuerza de ley en cuanto deriva de ley natural. Y si en algo está en desacuerdo con la ley natural, ya no es ley, sino corrupción de la ley. ${ }^{67}$

Existen otros lugares dónde Tomás de Aquino hace alguna alusión al tema que venimos tratando, pero en ninguno de ellos afirma expresamente que la ley injusta no sea ley. Para mencionar algún otro pasaje citaremos lo señalado por el Aquinate en la misma Summa Tehologiae, pero esta vez en la cuestión 96 artículo 4, cuando al preguntarse si las leyes humanas obligan en el fuero de la conciencia, Tomás de Aquino dirá: "Por lo cual, tales leyes no obligan en el foro de la conciencia...." 68

Estas y otras referencias, ${ }^{69}$ nos muestran claramente como Tomás de Aquino no realiza nunca la afirmación de que la ley injusta no sea ley, sus referencias son completamente distintas y mucho más complejas de analizar sobre las cuales no nos detendremos por el momento.

El segundo asunto que ofrecimos abordar es el tema relativo a la obediencia de las leyes injustas. Para ello daremos continuidad a la referencia hecha por Tomás de Aquino en la cuestión 96, artículo 4, ahí el de Aquino nos dice claramente que tales leyes no obligan en conciencia, completando su idea al señalar que esas leyes no han de

67 Tomás de Aquino, Summa Tehologiae, I-II, q. 95, a. 2, c.

68 Ibidem, q. 96, a. 4, c.

69 Cfr. Massini Correas, Carlos, I., y García-Huidobro, Joaquín, "Valoración e inclusión en el derecho." La máxima "Lex injusta non est Lex" y la iusfilosofía contemporánea", en varios autores, Razón jurídica..., cit., pp. 122 y 123. 
¿DERECHO NATURAL O MORAL? COMENTARIOS CRÍTICOS...

obedecerse, "a no ser que se trate de evitar el escándalo o el desorden, pues para esto el ciudadano está obligado a ceder su derecho".70

Los comentadores del texto anterior han establecido algunos matices que vale la pena señalar. Así, por ejemplo, siguiendo la doctrina de Tomás de Aquino, los autores han establecido dos supuestos por lo que a la inobservancia de las leyes se refiere: el primero de ellos es cuando una ley tiránica se desvía de su orientación original que es el bien común. Aquí cabe la posibilidad de una obligación colateral de obedecer la ley cuando la desobediencia de la misma trae mayores perjuicios al bien común. En este caso "la obligatoriedad no deriva de la ley misma, sino de una exigencia de prudencia, que nos lleva a evitar daños particularmente graves al bien común si no existe una razón justificada". ${ }^{71}$

El segundo supuesto es cuando las leyes injustas mandan directamente a la persona realizar un mal grave, por ejemplo, ir contra de un bien humano básico, como puede ser el caso de la muerte de un inocente; aquí Tomás de Aquino es muy claro: nunca es lícito obedecer a estas leyes. ${ }^{72}$

En resumen, en ambos supuestos el derecho natural, antes que la moral, posibilita la objeción de conciencia. En un escenario, porque incluso en el supuesto de que no se tenga mandado hacer algún mal sino sólo soportarlo, por ejemplo, pagar impuestos desorbitados, si no hay razones fuertes en favor del bien común o del orden público que lo justifique moralmente, la obediencia a la ley se debe omitir. ${ }^{73}$ Y, el segundo supuesto es cuando se manda realizar positivamente un mal grave, es decir, un ataque directo a un bien humano básico en términos de John Finnis, aquí no se debe nunca y bajo ninguna circunstancia obedecer la ley injusta. ${ }^{74}$

70 Tomás de Aquino, Summa Tehologiae, I-II, q. 96, a. 4. c.

71 Cfr. Massini Correas, Carlos, I., y García-Huidobro, Joaquín, "Valoración e inclusión en el derecho." La máxima "Lex injusta non est Lex" y la iusfilosofía contemporánea, en varios autores, Razón jurídica..., cit., p. 127.

72 Tomás de Aquino, Summa Tehologiae, I-II, q. 96, a. 4. c.

73 Cfr. Massini, Correas, Carlos, I., y García-Huidobro, Joaquín, "Valoración e inclusión en el derecho." La máxima "Lex injusta non est Lex" y la iusfilosofía contemporánea, en varios autores, Razón jurídica..., cit., p. 128.

74 Cfr. idem. 


\section{EL DERECHO NATURAL COMO FACILITADOR DE LA EFICACIA DEL DERECHO}

El sexto argumento que desarrolla Vigo en el trabajo hace referencia a la eficacia del derecho, es decir, a porqué las normas jurídicas son obedecidas por los ciudadanos a los que van dirigidas. Ya se puede apreciar que este tema pareciera corresponder más a un estudio de sociología jurídica y no de filosofía del derecho, mucho menos de iusnaturalismo o de axiología jurídica. Pero también en este punto el derecho natural aristotélico-tomista tiene mucho que aportar.

Curiosamente, el resumen de este razonamiento lo expone Vigo en las primeras líneas del argumento siguiente. Para este pensador — de ahí el título de este epígrafe- la moral ayuda en la observancia y cumplimiento de las normas jurídicas. Dirá el profesor argentino en la parte conducente de su escrito: "Hasta aquí hemos hablado de la eficacia del derecho en tanto cumplimiento voluntario de la norma, lo cual favorece el efecto pedagógico que se propone y evita los costos de su incumplimiento...."

Como sabemos, en el positivismo jurídico el tema de la eficacia de las normas ha recibido especial atención, y sobre este tema dicha corriente ha escrito mucho; sólo recordemos cómo para el más importante positivista del siglo XX como fue Hans Kelsen la eficacia de un sistema normativo es condición de validez del mismo, dicho en otras palabras, si un sistema normativo considerado en su unidad no es eficaz entonces tampoco puede ser válido. ${ }^{75}$

Ahora bien, las razones por las que un sistema normativo es eficaz pueden variar, y van desde observar una norma por el temor a la sanción (si una norma no se cumple el infractor de la misma puede ser castigado), hasta la misma consideración voluntaria de obede-

75 Kelsen señala en la parte conducente: “...la eficacia del orden jurídico, como un todo, y la eficacia de una norma jurídica aislada son, junto con el acto de instauración normativa, condición de la validez; y la eficacia es condición en el sentido de que un orden jurídico como un todo, y una norma jurídica aislada, no es considerada ya válida, cuando ha cesado de ser eficaz". Kelsen, Hans, Teoría pura del derecho..., cit., p. 223. 
¿DERECHO NATURAL O MORAL? COMENTARIOS CRÍTICOS...

cerla simplemente por convicción, es decir, por creer que cumplir con la norma es lo correcto, es lo justo.

¿Es la moral el criterio que puede ayudar a una mejor y más espontánea obediencia de las normas, o hay razones jurídicas - de derecho natural- que del mismo modo pueden motivar la obediencia espontánea de las mismas?

Que el positivismo jurídico haya dedicado esfuerzos encomiables para explicar el asunto de la eficacia no quiere decir que el derecho natural haya sido omiso en tratar el tema. Así, desde el punto de vista del derecho natural, y no desde la moral, Tomás de Aquino establecerá la necesidad de que existan leyes, preguntándose sobre si fuera útil la institución de éstas por parte de los hombres. Aquí el Aquinate dirá que tal instauración es especialmente necesaria y útil, teniendo como objetivo primario el establecimiento de la paz y la virtud de los hombres. ${ }^{76}$ Esta es la razón por la que se instituyen las leyes. Más adelante señalará en la misma cuestión y en el mismo artículo que: "A los hombres bien dispuestos se les induce más eficazmente a la virtud recurriendo a la libre persuasión que a la coacción. Pero entre los mal dispuestos hay quienes solo por coacción pueden ser conducidos a la virtud". ${ }^{77}$

Las referencias a Tomás de Aquino nos colocan delante de uno de los temas más relevantes en el ámbito del derecho natural y el derecho positivo para explicar la eficacia de la ley, este es, la referencia a la vis directiva y la vis coactiva de la ley.

Como señalamos anteriormente, para el iusnaturalismo en general y particularmente para Tomás de Aquino, la ley positiva humana no sólo no puede dejarse de lado, sino que es considerada vital para la convivencia humana. Sin embargo, habría que aclarar que la manera en la que ha de comprenderse esta positividad es diferente al positivismo normativista.

Si se observa con detenimiento, para el pensamiento de Tomás de Aquino, el cumplimiento y realización de la ley no es por el temor a la sanción, como han pensado muchos positivistas, sino fundamental y principalmente por la persecución y ejercicio de la virtud. Así,

76 Tomás de Aquino, Summa Tehologiae, I-II, q. 95, a. 1.

77 Idem. 
y en sintonía con todo lo que había dicho antes sobre la ley, Tomás de Aquino reconoce que el hombre, teniendo libertad para no observarla, opta por reconocerla pues, en términos normales, su inteligencia y libertad le revelan una realidad percibida como un bien, como algo valioso, como algo bueno que debe ser cumplido y observado. Es entonces por alcanzar la virtud por la que se establecieron las leyes humanas, no sólo en el caso de los hombres de bien, sino incluso de aquellos otros rijosos, los mal dispuestos.

En este argumento está implícita ya la idea de naturaleza humana (clave para entender la razón práctica en Tomás de Aquino) que mueve al hombre hacia la realización de su finalidad, la cual es alcanzar el perfeccionamiento humano através de la virtud. ${ }^{78}$ La ley así entendida (vis directiva) no se impone, sino que se propone. Dice Aubot:

Puesto que el hombre no está irremediablemente empujado por una necesidad que proveyera por él a su bien (caso de los seres sin razón) debe proveerse él libremente, siguiendo una ley que revela, sin embargo, carácter obligatorio, pues expresa un vínculo real entre lo que es y lo que debe llegar a ser. Y este vínculo expresado por la ley lo descubre su razón natural y ella es su regla; a su voluntad incumbe realizarlo. La función de la ley es, por ende, llevar al hombre a realizarse plenamente a sí mismo; ella es la condición natural y necesaria del empleo de la libertad y, por paradójico que parezca, la ley sólo es obligatoria porque el hombre es libre. ${ }^{79}$

Esta inducción a la rectitud es lo que Tomás de Aquino llamó vis directiva, siendo claro entonces que desde la perspectiva iusnaturalista no es la obligación coactiva la que define esencialmente la ley, ni tampoco determina su eficacia, sino su propiedad esencial que es dirigir al hombre a la virtud la que marca tal eficacia. ${ }^{80}$

78 Cfr. George P., Robert, "Natural Law and Human Nature", en Natural law theory. Contemporary Essays..., cit., p. 34.

79 Aubert, Jean-Marie, Ley de Dios. Leyes de los hombres, Barcelona, Herder, 1979, p. 49.

80 Cfr. ibidem, p. 50. 
La vis coactiva, por su parte, aparece no como esencia de la ley sino como algo accesorio a ella. No dejando nunca de lado su función reguladora, la ley ha de auxiliarse de la coacción, e incluso de la fuerza física para el caso de aquellos que han decidido apartarse de su observancia. Así, la observarán por la amenaza de una sanción o pena, es decir, por la privación de un bien de orden físico o moral. La pena es pues una especie de complemento de la ley y de su obligación, de ahí que el establecimiento de las penas sea incluso una exigencia del derecho natural ${ }^{81}$ como lo veremos en el siguiente argumento del profesor argentino.

\section{EL DERECHO NATURAL COMO COMPLEMENTO DE LA COACCIÓN JURÍDICA}

El siguiente argumento presentado por el profesor Vigo se refiere al papel complementario que juega la coacción en el cumplimiento del derecho.

También en este punto - como en los demás- el profesor argentino refiere el lugar que ocupa el elemento coercitivo dentro de la corriente positivista-normativista del derecho, para ello cita a Kelsen quien, como sabemos, entendió que dicho elemento desempeñaba un papel central, casi definicional del derecho. ${ }^{82}$ Sin embargo, Vigo va explicando cómo después de la Segunda Guerra Mundial y en los tiempos más recientes, la actual teoría del derecho, si bien reconoce la necesaria presencia de la coacción en el derecho, éste ha dejado de confiar solamente en ella para su cumplimiento, y hoy se orienta a incorporar medios que apelan a la conciencia ética y la intención del ciudadano para ser observado. No esconde Vigo en este punto la idea de que el derecho está llamado, igualmente, a jugar un papel educativo dentro de la sociedad.

¿Qué papel ocupa la coacción en la explicación general del derecho natural? ¿Es la coacción la nota esencial por la que se identifica

81

82 Cfr. Kelsen, Hans, Teoría pura del derecho..., cit., pp. 46 y 47. 
al derecho y por tanto al derecho natural? ¿Qué sistema de garantías tiene el derecho natural para hacerse efectivo?

Como repetidamente se ha expresado en este escrito, el derecho natural es derecho, y una de las notas que lo caracteriza es que éste es coactivo, de modo que tal coacción forma parte de lo que algunos iusnaturalistas han llamado su sistema de garantías con la que se asegura la efectividad del derecho natural. Sin embargo, se tiene que señalar que si bien la coacción - generalmente representada por el empleo de la fuerza - es fundamental para el derecho, no es su elemento constitutivo, es decir, el derecho no depende de ésta para que exista. Dice el profesor español Javier Hervada:

La idea principal a tener en cuenta es que el sistema de garantías es una consecuencia de la obligatoriedad del derecho, que está en el orden de la ayuda a su efectividad, pero que no pertenece a su esencia: la falta de aplicación del sistema de garantías no destruye al derecho, aunque a veces pueda dejarlo inoperante. ${ }^{83}$

La pregunta que se formula el maestro español, sin duda, es la pregunta clave para entender este tema: ¿Cuál es el sistema de garantía de efectividad del derecho natural?. Respondiéndose con la mayor claridad posible "es el mismo que el propio derecho positivo". ${ }^{84}$ Esta tesis es central a la hora de entender el elemento coercitivo del derecho, porque como todos los naturalistas (comenzando por Aristóteles) nos han explicado, el derecho es un solo orden jurídico, el cual se compone de un elemento natural y un elemento positivo. Ambos forman un único sistema de normas, es decir, un solo sistema normativo, de modo que las garantías de efectividad que se encuentran previstas por el derecho positivo, serán las mismas que han de reconocerse para el derecho natural. ${ }^{85}$

Lo anterior parece que no amerita mayor discusión, pero la situación se complica cuando se introducen otros supuestos. Así, por ejemplo, Cristóbal Orrego se ha formulado una pregunta que vale la pena traer a colación por la importancia de la misma, y porque

83 Hervada, Javier, Introducción crítica al derecho natural..., cit., p. 182.

84 Idem.

85 Cfr. idem. 


\section{¿DERECHO NATURAL O MORAL? COMENTARIOS CRÍTICOS...}

vendría a complementar la respuesta a la cuestión que venimos tratando: Si tal y como hemos establecido, el sistema de garantías del derecho natural es el mismo que el del derecho positivo ¿qué pasaría si este último no estableciera coacción alguna, el derecho natural se quedaría sin la posibilidad de ser cumplido y por tanto de ser eficaz? ¿Qué sucedería con la protección de lo justo natural, por ejemplo, de un derecho humano, que no fuera puesto, o establecido por el derecho positivo?

Dice el mismo Orrego a lo anteriormente planteado:

...Esta "fuerza" del derecho natural se da en todas partes (aquí nos está recordando a Aristóteles en la referencia que el filósofo hace en el libro V de la Ética a Nicómaco - JSS-); en primer lugar, porque esa exigencia de su "consagración" con los medios de coacción y su vigencia "en" el mismo derecho humano como "parte suya" es un hecho que no sufre excepciones en los puntos más fundamentales (homicidio, robo, etcétera); en segundo lugar, porque allí donde la fuerza de una voluntad (poder estatal) se opone a la fuerza -igual en todas partes- de lo que es "lo justo" por naturaleza vence de hecho o, al menos, hay una sanción "no organizada" pero real contra su violación. ${ }^{86}$

La idea es clara entonces, si por cualquier circunstancia la plasmación de un derecho humano no trajera aparejada una garantía de observancia en caso de violación, es decir, aunque no existiera una sanción institucionalizada establecida positivamente, lo justo por naturaleza ya contiene, en sí mismo, una sanción, a la que podríamos llamar "sanción natural".

El supuesto anterior es, en todo caso, extremo, el imaginario normal es la necesidad de la instauración de las leyes - derecho positivo- con las garantías que hagan efectivo el derecho natural. Al respecto y en diferentes lugares Tomás de Aquino señala que: "Las leyes fueron instituidas para que por ellas se modere la audacia humana, quede protegida la inocencia en medio de los malvados y se

86 Orrego Sánchez, Cristóbal, Analítica del derecho justo. La crisis del positivismo jurídico y..., cit., p. 63. 
refrene a éstos, mediante el temor del suplicio, incluso la posibilidad de qué hagan daño...." ${ }^{87}$

Y más adelante señala:

Más como hay también individuos rebeldes y propensos al vicio, a los que no es fácil persuadir con palabras, a estos será necesario retraerlos del mal mediante la fuerza y el miedo, para que así, desistiendo, cuando menos, de cometer sus desmanes, dejasen en paz a los demás, y ellos mismos, acostumbrándose a esto, acabarán haciendo voluntariamente lo que antes hacían por miedo al castigo, llegando así a ser virtuosos. Ahora bien, esta disciplina que obliga mediante el temor a la pena, es la disciplina de la ley. Luego era necesario para la paz y la virtud de los hombres que se instituyeron las leyes... ${ }^{88}$

Como podemos comprobar, la moral no actúa como complemento de la coerción jurídica, sino que es lo justo positivo - basado en lo justo natural- el que establece el sistema de garantías, entre ellas, por supuesto, la coacción, pero no es la única. Incluso en el supuesto de que en el derecho positivo no se estableciera coacción alguna, la propia condición de lo justo natural la reconocería.

\section{EL DERECHO NATURAL ABIERTO A OTROS SABERES CIENTÍFICOS}

En el penúltimo argumento de su escrito, Rodolfo Vigo describe cómo el modelo jurídico que se enseñó y estudió en el siglo XVIII y principalmente en el XIX, presentó al derecho en forma aislada de otras ciencias sociales, prescindiendo de cualquier contacto con ellas. Como todos conocemos, los esfuerzos que se hicieron en esos siglos y que alcanzaron incluso a la primera mitad del siglo XX, tuvieron como objetivo hacer del derecho una verdadera ciencia, identificada por el rasgo más característico de éstas como es su carácter avalorativo, en este punto Kelsen fue sin duda uno de sus mejores exponentes. El objetivo y propósito de esta tarea fue siempre claro: separar al derecho de la moral.

88 Idem. 


\section{¿DERECHO NATURAL O MORAL? COMENTARIOS CRÍTICOS...}

En rigor, dicho esfuerzo tuvo un resultado limitado pues incluso desde las mismas filas del positivismo jurídico pronto se mostraron sus reducidos alcances. Hart, por ejemplo, claramente reconocería la significativa relación que de hecho tiene el derecho con otros saberes, particularmente con la moral.$^{89}$ Por otra parte, con mayor énfasis, críticos tan destacados del positivismo jurídico como Dworkin establecerán sin reparos la inescindible relación existente entre el derecho y la moral. ${ }^{90}$

Tomando en cuenta los anteriores argumentos, una buena parte de la teoría jurídica contemporánea ha establecido las muchas relaciones que existen entre el derecho y el resto de saberes normativos por vía de la rehabilitación de la razón práctica, algo que - como lo dice Vigo en su escrito- hoy es una de las más importantes características de la teoría del derecho contemporánea.

No es mi intención dar cuenta de todo este gran movimiento teórico de rehabilitación, baste para los efectos de este escrito referirme a dos argumentos muy puntuales: i) reseñar las características específicas de la razón práctica aristotélico-tomista, donde se puede comprobar que sólo este tipo de razón es capaz de establecer puntos de encuentro con saberes, políticos o éticos y hasta económicos, y ii) en segundo lugar - y esto es quizá lo más importantemostrar cómo lo que hoy se presenta como novedad a propósito de las relaciones entre el derecho y la moral u otros conocimientos, ya el derecho natural lo había explicado desde siempre.

Es muy pedagógico remitirnos a lo señalado por Robert Alexy cuando habla de la mencionada rehabilitación de la razón práctica, recodándonos que existen, al menos, cuatro grandes modelos: la aristótelica, la hobbesiana, la kantiana, y aquella otra que hunde raíces en Nietzsche, a la cual se le suele llamar crítica. ${ }^{91}$

89 "Tal como un sistema jurídico contiene obviamente elementos estrechamente conectados con los casos simples de órdenes respaldadas por amenazas, así, en forma igualmente obvia, contiene elementos estrechamente conectados con ciertos aspectos de la moral". Hart, H. L. A., El concepto de derecho, cit., p. 9. Entre otros muchos lugares.

90 Cfr. Dworkin, Ronald, M., “¿Es el derecho un sistema de reglas?”, Cuaderno de Crítica, UNAM, 1977, pp. 18 y 19.

91 Cfr. Alexy, Robert, El concepto y validez del derecho, 2a. ed., trad. de J. M. Seña, 
Evidentemente que la razón práctica que tratamos es la radicada en Aristóteles y continuada después por Tomás de Aquino ¿qué características identifican este particular modelo de razón práctica y, sobre todo, ¿cómo ésta razón mantiene puntos de conexión con otras disciplinas normativas?

Lo primero que tendríamos que señalar es que este particular tipo de razón práctica no explica las disciplinas que la integran en forma separada, es decir, independientes unas de las otras, porque entiende que la acción humana es una y única, y que entre la política, el derecho y la ética existen vínculos insoslayables. Sólo desde esta posición realista (iusnaturalista) radicada en la realidad humana tal cual es, será posible fundamentar racionalmente dichas materias prácticas.

Iusnaturalistas como Aristóteles nos habían recordado en la $\mathrm{Me-}$ tafísica que la filosofía fuera llamada ciencia de la verdad cuando se tratase de la ciencia teórica, y obra cuando fuera denominada ciencia práctica. ${ }^{92}$ Por su parte, el libro V de la Ética a Nicómaco —entre otros lugares - se encuentra dedicado íntegramente a reconocer las necesarias conexiones entre el derecho; la política; la ética y la economía. ${ }^{93}$ Establecido lo anterior, pasemos ahora a mencionar cuáles son sus caracteres más generales.

El primer carácter de esta razón práctica el propio Aristóteles nos la recuerda, y consiste en establecer el hecho de que este tipo de razón no se encuentra separada de la razón especulativa. De modo que la acción humana tendrá siempre como antecedente un acto racional establecido por la razón especulativa. Así, un acto volitivo o normativo como son los relativos al derecho, la política o la ética tienen antes un razonamiento teórico acerca de lo que es verdadero y bueno. ${ }^{94}$

Barcelona, Gedisa, 1997, p. 133.

92 Aristóteles, Metafísica, II, 993b, 20.

93 Aristóteles, Ética Nicomáquea, V, 1133ạ , 20.

94 “...Lo que en el pensamiento son la afirmación y negación, son en el deseo la persecución y la huida: de modo que, puesto que la virtud moral es una disposición relativa a la elección y la elección es un deseo deliberado, el razonamiento tiene que ser verdadero y el deseo recto para que la elección sea buena, y tiene que ser lo mismo lo que la razón diga y lo que el deseo persiga". Ibidem, VI, 2, 139å , b. 


\section{¿DERECHO NATURAL O MORAL? COMENTARIOS CRÍTICOS...}

Una segunda característica es que es un operable de acción inmanente, es decir, que la razón práctica rige la actividad humana hacia un fin, y su objetivo sería orientar dicha acción hacia lo que el hombre debe realizar. Y así, el iusnaturalista Aristóteles nos dira: "Toda arte y toda investigación, y del mismo modo toda acción y elección parecen tender a algún bien, y por eso se ha dicho con razón que el bien es aquello a que todas las cosas tienden". ${ }^{95}$

La tercera característica es que el fin anunciado consiste en la realización de un bien humano perfecto. Este bien o lo bueno al que tiende la acción humana, busca la realización del hombre que la lleva a efecto. Se encuentra, por tanto, la razón especulativa y práctica en íntima relación con la perfección humana. ${ }^{96}$

Todo lo anterior es iusnaturalismo y como conclusión tendríamos que decir que estas tres características que identifican la razón práctica, es decir, la acción humana, son aplicables igual para el derecho que para la ética, lo mismo para la política que para la economía. De modo que el derecho, desde el punto de vista del iusnaturalismo clásico, nunca ha sido considerado insularmente, para emplear la terminología de Vigo.

En sintonía con el razonamiento aristotélico, Tomas de Aquino cita en varios lugares de la Summa Tehologiae el argumento de la razón práctica, y en el mismo sentido que el Estagirita se pregunta por el fin de la acción humana, señalando que éste "se comporta como principio de las cosas realizables". Así, pone el ejemplo de la acción de un médico, donde la salud se comporta como fin. Aquí, la salud no entra en la elección del médico, sino la supone como principio. ${ }^{97}$ 0 en el caso de la pregunta sobre si la ley corresponde a la razón, señalará claramente que ésta se encuentra ordenada a la operación, a un bien, como puede ser, por ejemplo, el bien común. ${ }^{98}$

De lo anterior podemos apreciar cómo en el derecho natural clásico la referencia a la razón práctica muestra a las claras las íntimas relaciones que existen entre el derecho y la moral, o entre ésta y la 
política, o entre la moral y la economía. Esta es una de las razones por las que un pensador iusnaturalista está en mejores condiciones de criticar un sistema político cuando éste es tiránico, o un sistema económico cuando es desigual, o una ley violatoria de derechos humanos como injusta. Siendo dichas actividades propias de la acción humana, la misma está guiada por una misma razón práctica. Con esto se puede comprobar que el iusnaturalismo siempre ha explicado en derecho en un contexto más general de la acción humana, y por tanto en un análisis más amplio de las disciplinas sociales.

\section{EL DERECHO NATURAL COMO ELEMENTO GARANTIZADOR DE LOS MEJORES OPERADORES JURÍDICOS (PRINCIPALMENTE LOS JUECES)}

Un último argumento reseñado por el profesor Vigo se refiere a la importancia que tiene la moral en el ejercicio del derecho por parte de los operadores jurídicos, principalmente los jueces. El juez, sin duda, tiene un papel protagónico en el derecho, entre otras cosas porque es quien se ocupa de aplicarlo, es decir, establecer lo justo en el caso concreto. Para Vigo, el positivismo legalista prestó muy poca atención a la formación ética de los juristas, particularmente de los jueces, pues puso énfasis, exclusivamente, en señalarles que su labor consistía en aplicar la ley, y en tareas tan significativas como la interpretación del derecho, dejar al más grosero voluntarismo tan importante labor. En esto, Kelsen podría ser el mejor ejemplo para citar.

Sin embargo, esta manera de pensar el derecho en acción ha ido cambiando paulatinamente en beneficio de la profesión jurídica, pues en muchas partes del mundo donde existen culturas distintas a la continental-europea como pueden ser, por ejemplo, la cultura del common law, importa, y de manera sobresaliente, la calidad de los juristas que trabajan en el derecho en acción, es decir, con el derecho que se aplica cotidianamente. Esta exigencia es aún mayor en el caso de los jueces.

Sin duda, en el aspecto que venimos comentando el profesor Vigo ha sido uno de los pioneros, principalmente por lo que se refiere a la ética de los jueces en el contexto Iberoamericano, pero también hay que decir que la exposición que ha hecho con tanta solidez no 


\section{¿DERECHO NATURAL O MORAL? COMENTARIOS CRÍTICOS...}

sería posible sin sus profundos conocimientos en la filosofía clásica, donde el tema de la formación y calificación de los operadores jurídicos, particularmente de los jueces, ha estado también siempre presente.

Para abordar el tema en cuestión, lo primero que tendría que considerarse es la concepción que del derecho se tenga y, consecuentemente, la visión que se posea de la figura del juez. Sobre el primer punto, hemos expresado en repetidas ocasiones que para el derecho natural la aplicación del derecho no es sólo la reproducción de la ley, sino que es decir lo justo, así el juez no está llamado exclusivamente aplicar la ley, sino a buscar cuál es lo justo de cada cual. A las claras se comprende entonces que el juez está esencial y fundamentalmente para hacer justicia, no para defender ideologías, por más progresistas que estas puedan presentarse. Así, al derecho natural siempre le ha importado que el juez no solamente sea un perito en derecho, es decir, un profesional que conozca su oficio, sino también le ha importado la persona del juzgador. El argumento esencial en este punto es que su formación no desconozca sino que haga suya la propuesta iusnaturalista, o realista, alejándose de cualquier interés ideológico, económico, familiar o de otra índole.

Orrego, sin duda, ha formulado la pregunta capital en este tema, la cual, aunque larga, vale la pena transcribir; dice el profesor chileno: ¿Cómo asegurar que el juez diga lo justo, natural y positivo, sin incurrir en "positivismo" (desconocer una exigencia de la naturaleza por apego al texto legal expreso) ni de "naturalismo" (desconocer una exigencia de la voluntad humana que verdaderamente "estatuye" lo justo donde no lo ha hecho el derecho natural, so pretexto de ser fiel a la moral o al "derecho natural mal" interpretados)?".99

En mi opinión, para responder cabalmente la pregunta anterior, es importante considerar como argumento clave la formación de los operadores jurídicos, principalmente los jueces. En tal formación es de vital importancia incorporar el argumento ético basado en virtudes, y más específicamente en las virtudes judiciales. Este tipo de

99 Orrego Sánchez, Cristóbal, Analítica del derecho justo. La crisis del positivismo jurídico..., cit., p. 65. 
modelo del juez ha sido el que siempre ha defendido la filosofía clásica de herencia aristotélico-tomista.

Son varios los lugares en los que Aristóteles habla de la virtud de los jueces. Así, por ejemplo, en la Ética Nicomáquea se puede leer: “...Es por esto por lo que aquellos que discuten recurren al juez, y al acudir al juez es acudir a la justicia, porque el juez quiere ser como una personificación de la justicia". ${ }^{100}$

Por su parte, en la obra de Tomás de Aquino se reconoce la importancia de las virtudes, así, por ejemplo, se puede comprobar cómo en el Aquinate hay un extenso tratamiento de las virtudes propias de la función judicial, como son, por ejemplo, la prudencia, la justicia, la fortaleza y la templanza; pero también la humildad o la sinceridad.

La importancia de las virtudes anunciadas se ve reflejada en los razonamientos que la actividad judicial está llamada a realizar. Así, por ejemplo, el juicio recto que realiza una persona sobre una cosa (actividad esencial de cualquier juzgador) debe cumplir al menos tres requisitos esenciales: primera, que proceda de una inclinación de justicia; segunda, que emane de la autoridad del que preside, y tercera, que sea pronunciado según la recta razón de la prudencia. ${ }^{101}$

Como vemos claramente, la tradición iusnaturalista clásica no desestima la formación ética basada en virtudes de los jueces, porque se da cuenta de la importante labor a la que están llamados tales operadores del derecho. Llegados a este punto, conviene formularse una última pregunta ¿qué importancia tienen las virtudes en la praxis judicial?, o dicho de otra forma ¿para qué le sirve al juez contar con virtudes?

Sobre la pregunta que se ha formulado podríamos decir que son muchas las funciones que se le pueden atribuir a las virtudes judiciales; ${ }^{102}$ sin embargo, sólo centraremos nuestra atención en tres de ellas.

En primer lugar, es claro que el juez que hace suyas las virtudes judiciales, estará en mejores condiciones para realizar de la manera

100 Aristóteles, Ética Nicomáquea, V, 1132 a. 19-25

101 Tomás de Aquino, Summa Tehologiae, I-II, q. 60. a 2.

102 Cfr. Saldaña Serrano, Javier, El papel de la ética judicial en el nuevo modelo de juez del Estado constitucional de derecho, México, UNAM-Porrúa, 2016, pp. 99 y 100. 
más óptima la deliberación a la que está llamado. Dicho juzgador estará mejor dispuesto para conocer todos los aspectos y circunstancias que encierran los problemas judiciales. Igualmente estará en óptimas condiciones para saber elegir el mejor derecho aplicable, así como para justificar de mejor manera su decisión. ${ }^{103}$

Lo anterior abre la posibilidad a la función que probablemente sea la más importante de sus tareas, esto es, asegurar que la decisión que tome el juez sea la correcta y justa. Esto porque el compromiso que ha hecho con la virtud le permitirá no sólo poseer un mejor hábito para pensar, sino sobre todo para decidir. De este modo, la confianza en la sentencia de los jueces virtuosos será mayor que la de aquellos que no están comprometidos con dichos hábitos. ${ }^{104}$

Finalmente, otra función importante de las virtudes judiciales consistirá en la imagen pública — tan necesaria- de los jueces. No olvidemos que los jueces juegan hoy quizá el papel más relevante en el Estado de derecho y que la apariencia de su figura importa tanto como la realidad del trabajo que realizan. Ambos le sirven al juez para legitimar su labor ante la sociedad, de ahí que en el imaginario popular que se tiene de los jueces se diga que estos son como la mujer del César, no sólo tiene que serlo, sino también parecerlo. Esto también es derecho natural y no moral.

\section{Conclusiones}

Primera. La existencia y validez de las normas jurídicas no depende únicamente de los puros aspectos formales de su creación. Un sistema normativo existe y es obligatorio porque tiene su origen en la deliberación racional que se lleva a efecto y que conducen a identificar el bien (o los bienes) que le ayudan en su realización como personas y como miembro de una colectividad. Con esto se comprende cómo al lado de los aspectos formales, para el derecho natural la razón determina el bien o los bienes que la voluntad ha de actualizar.

103 Cfr. Amaya Navarro, Amalia María, Virtudes judiciales y argumentación. Una aproximación a la ética jurídica, México, 2009, p. 35.

104 Cfr. ibidem. 
Segunda. El positivismo jurídico nos enseñó que la creación de las leyes correspondía a la voluntad de soberano, y que en tal facultad residía el contenido de la norma - la que él quisiera darle-, pero el positivismo contemporáneo nos ha venido a decir que corresponde a la razón y no a la voluntad la creación de tales normas. Hart en este punto puede ser el mejor ejemplo a citar. Sin embargo, que la ley sea producto de la razón y no sólo de la voluntad nos lo había enseñado el iusnaturalismo clásico desde siempre. Así, para el derecho natural es la concurrencia de ambas facultades humanas la que crea la ley. De modo que la voluntad no actúa sin un fin definido, sino que este fin, que tiene naturaleza de bien, es aprehendido por la razón y perseguido por la voluntad, asegurándonos con esto un mejor derecho.

Tercera. El derecho natural siempre ha defendido la tesis de que para la mejor aplicación del derecho es necesario poner énfasis en dos aspectos importantes: una comprensión cabal de la figura del juzgador como protagonista del derecho en acción por su capacidad de decisión, y un compromiso de éste con el conjunto de las virtudes prácticas, particularmente con la virtud de la prudencia y de la justicia. Con tales argumentos se garantiza una mejor aplicación del derecho, no dejando a la moral tal expectativa.

Cuarta. Uno de los objetivos más fuertemente perseguidos y buscados por el iusnaturalismo clásico es el de identificar al derecho natural como científico, calificación ésta que no puede ser patrimonio sólo de una visión del derecho como puede ser la normativista. De ahí que pueda aceptarse que exista una ciencia del derecho natural, entendida ésta como un conocimiento causal y demostrativo de las cosas por sus causas a partir de primeros principios aprehendidos en forma evidente. De este modo, el derecho natural no puede ser calificado como un ideal, sino enrraizado en una metafísica del ser que se explica como una ciencia de carácter práctica.

Quinta. La desobediencia a las leyes injustas ha estado siempre presente en el debate iusnaturalista, pero lo que se ha de señalar es que ningún representante de esta corriente ha dicho jamas que la ley injusta no es ley. Lo que sí se ha destacado es que dichas leyes no lo son en un sentido focal, es decir, tienen sólo la apariencia de ley. Establecido esto, se puede afirmar que una ley injusta se ha de obedecer cuándo su inobservancia acarree un atentado grave al bien 
¿DERECHO NATURAL O MORAL? COMENTARIOS CRÍTICOS...

común, de no haberlo no se tiene que obedecer. Pero nunca deben ser obedecidas si atentan contra un bien humano básico.

Sexta. La eficacia de la ley para el iusnaturalismo no depende de la existencia de sanciones como lo pensó el positivismo. Para esta corriente del pensamiento, la observancia y por tanto la eficacia de la ley, depende esencialmente de la persuasión que el individuo esté dispuesto a aceptar por un bien mayor como es el argumento de la virtud, lo cual le lleva a un reconocimiento de la misma y por tanto a una observancia, casi diríamos espontánea, de la misma ley. Es la virtud y no la coacción lo que hace eficaz una norma, en una especie de exigencia natural.

Séptima. La coacción es un elemento importante en el derecho, pero no es constitutivo a éste. Considerando que el derecho se integra por un elemento natural y uno positivo, el sistema de garantías del primero vendrá siendo establecido por lo justo positivo, y en el caso de que éste no las estipulara, la condición de lo justo natural las reconocería para exigirlas.

Octava. La actual teoría del derecho se caracteriza por los esfuerzos de entenderla en el contexto más general de las disciplinas prácticas, es decir, que el derecho de hoy difícilmente puede entenderse en forma insular. Este entendimiento lo había hecho siempre el derecho natural clásico para el cual la razón práctica es una, y las materias que lo integran guardan entre sí íntimas relaciones. Así, el derecho natural es derecho (lo justo), pero tiene una estrecha conexión con la moral, con la política, con la economía y, en general, con el resto de las ciencias sociales.

Novena. Dentro de las muchas notas identificatorias que distinguen hoy la reflexión jurídica está el tema de las virtudes prácticas, particularmente de cómo éstas juegan hoy un papel fundamental en la capacitación jurídica, especialmente la que concierne a los jueces, los cuales no pueden seguir siendo considerados como voceros de la ley, sino que su labor ha de estar caracterizada por ese real compromiso con la concreción de la justicia. Para ello se requiere una formación iusnaturalista, porque la corriente de pensamiento que más y mejor ha explicado el tema de las virtudes prácticas ha sido precisamente el derecho natural clásico. 


\section{REFERENCIAS}

Aquino, Tomás de, Summa Tehologiae, 3a. ed., Madrid, B.A.C., 1997. ARIstóteles, Metafísica, 2a. ed., a cargo de Valentín García Yebra, Madrid, Gredos, 1990.

ARIstóteles, Ética Nicomáquea, Madrid, Gredos, 2003.

ALEXY, Robert, El concepto y validez del derecho, 2a. ed., trad. de J. M., Seña, Barcelona, Gedisa, 1997.

AmaYA Navarro, Amalia María, Virtudes judiciales y argumentación. Una aproximación a la ética jurídica, México, 2009.

AtienzA, Manuel, El derecho como argumentación, Barcelona, Ariel, 2006.

Aubert, Jean-Marie, Ley de Dios. Leyes de los hombres, Barcelona, Herder, 1979.

Austin, John, Sobre la utilidad del estudio de la jurisprudencia, México, Nacional, 1974.

Ballesteros, Jesús, Sobre el sentido del derecho, 2a. ed., Madrid, Tecnos, 1986.

Boввio, Norberto, El positivismo jurídico, Madrid, Debate, 1993.

Boyle, Joseph, "Natural Law and the Ethics of Traditions", en Robert, P. George (ed.), Natural law theory. Contemporary Essays, Oxford, Oxford University Press, 1995.

Dworkin, Ronald, M., “¿Es el derecho un sistema de reglas?”, Cuaderno de Crítica, UNAM, 1977.

Finnis, John, Estudios de Teoría del derecho natural, México, UNAM, 2017.

FulLer, L. Lon, The Morality of Law, Yale University, U.S.A, 1964, trad. de Cast. F. Navarro, La moral del derecho, México, Trillas, 1967.

GARzón VALDÉs, Ernesto, “Derecho y Moral”, en VÁzQuez, R. (comp.), Derecho y moral. Ensayos sobre un debate contemporáneo, Barcelona, Gedisa, 1998. 
GeoRge, P. Robert, "Natural Law and Human Nature", en Robert, P. George (ed.), Natural law theory. Contemporary Essays, Oxford, Oxford University Press, 1995.

GómEz Robledo, Antonio, Ensayo sobre las virtudes intelectuales, México, Fondo de Cultura Económica, 1996.

Graneris, Giuseppe, Contribución tomista a la filosofía del derecho, Buenos Aires, Eudeba, 1973.

Hans Kelsen, Teoría Pura del Derecho, 16a. ed., México, Porrúa, 2009. HART, H., L., A., El concepto de derecho, trad. de Genaro R. Carrió, 2a. ed., Buenos Aires, Abeledo-Perrot, 1995.

HervadA, Javier, Cuatro lecciones de derecho natural. Parte especial, 3a. ed., Pamplona, Eunsa, 1993.

HervadA, Javier, Introducción crítica al derecho natural, 7a. ed., Pamplona, Eunsa.

HervadA, Javier, Lecciones propedéuticas de filosofía de derecho, Pamplona, Eunsa, 1992.

Hoвbes, Thomas, Leviatan, México, Fondo de Cultura Económica, 1994.

MacCormick, Neil, "Natural Law and the Separation of Law and Morals", en Robert, P. George (ed.), Natural Law Theory. Contemporary Essays, Oxford, Oxford University Press, 1995.

MARTínez Doral, José María, La estructura del conocimiento jurídico, Pamplona, Universidad de Navarra, 1963.

MASSini Correas, Carlos I. y García-Huidobro, Joaquín, "Valoración e inclusión en el derecho." La máxima "Lex injusta non est Lex" y la iusfilosofía contemporánea", en varios autores, $R a$ zón jurídica y razón moral. Estudio sobre la valoración ética en el derecho, México, Porrúa-U. Austral, 2012.

Montesquieu, Del espíritu de las leyes, 4a. ed., Madrid, Tecnos, 1998. Nino, Carlos Santiago, La validez del derecho, Buenos Aires, Astrea, 2003. 
OrRego SÁnchez, Cristóbal, Analítica del derecho justo. La crisis del positivismo jurídico y la crítica del derecho natural, México, UNAM, 2005.

Patiño Reyes, Alberto, La objeción de conciencia ante el derecho mexicano. ¿Incumplimiento del deber jurídico o libre ejercicio de un derecho humano?, México, Tiran Lo Blanch, 2021.

Preciado Hernández, Rafael, Lecciones de filosofía del derecho, México, UNAM, 1986.

Quintana, Martín Eduardo, Notas sobre el derecho natural en el iusnaturalismo, Buenos Aires, Educa, 2008.

SAldaña Serrano, Javier, El papel de la ética judicial en el nuevo modelo de juez del Estado constitucional de derecho, México, UNAM-Porrúa, 2016. 